Florida International University FIU Digital Commons

$12-1982$

\title{
Perceived and actual sex differences in attributional style for affiliative behavior
}

\author{
Gretchen A. Brown \\ Florida International University
}

DOI: 10.25148 /etd.FI14051855

Follow this and additional works at: https://digitalcommons.fiu.edu/etd

Part of the Psychology Commons

\section{Recommended Citation}

Brown, Gretchen A., "Perceived and actual sex differences in attributional style for affiliative behavior" (1982). FIU Electronic Theses and Dissertations. 1872.

https://digitalcommons.fiu.edu/etd/1872

This work is brought to you for free and open access by the University Graduate School at FIU Digital Commons. It has been accepted for inclusion in FIU Electronic Theses and Dissertations by an authorized administrator of FIU Digital Commons. For more information, please contact dcc@fiu.edu. 
The objectives of this thesis were threefold: (1) to review the concept of attributional style, (2) to demonstrate its applicability to affiliative behavior, and (3) to document the existence of actual and perceived sex differences in attributional style for affiliative behavior. To fulfill the first two objectives the development of attributional theory was traced from the Abramson, Seligman, and Teasdale (1978) presentation of the reformulated learned helplessness model through Weiner's (1979) examination of attributional style as a motivational feature of achievement behavior to the application of attribution theory to affiliative behavior. To fulfill the third objective the evidence detailing the sex differences in achievement and affiliative attributional styles was reviewed within the framework of perceptions of sex appropriate behavior. A study was then designed to assess both actual and perceived affiliative attributional sex differences. The Escovar, Brown, and Rodriguez Attributional Style Questionnaire for Affiliative Behavior was administered to 107 male and female University of Miami and Florida International University students. Each subject answered the questionnaire twice, once for themselves and once as if they were a member of the opposite sex. The results. indicated that the EBR-ASQ maintained previous levels of internal consistency and reliability. Analyses performed on the covariate of the order of perspective presentation 
were negative; all further analyses were performed without a covariate. The data were analyzed using a 2 (Sex) $x$ 2 (Perspective) X 2(Outcome) factorial, multivariate, repeated measures design with the three attributional dimensions serving as the dependent variable repeated measures. As expected all multivariate tests revealed that each of the three factors was a significant influence over all three of the dependent variables. Of the 21 univariate tests 12 of the main effect and two-way interactions were significant and one approached significance. Examination of the means revealed that of the eight significant main effects six were in the expected direction; of the four significant two-way interactions three were in the expected direction. Although the results were not totally supportive of the hypotheses they did support the thesis that affiliation is the female sex-role appropriate analogue to male achievement behavior. 
PERCEIVED AND ACTUAL SEX DIFFERENCES IN ATTRIBUTIONAL STYLE FOR AFFILIATIVE BEHAVIOR

by

Gretchen A. Brown

A thesis submitted in partial fulfillment of the requirements for the degree of

MASTER OF SCIENCE

in

PSYCHOLOGY

at

FLORIDA INTERNATIONAL UNIVERSITY

Committee in charge:

Professor Luis A. Escovar, Chairperson

Professor William M. Kurtines

Professor Fernando Gonzalez-Reigosa

December 1982 
To Professors Luis A. Escovar, Ph.D.; William M. Kurtines, Ph.D.; and Fernando Gonzalez-Reigosa, Ph.D.

This thesis, having been approved in respect to form and mechanical execution, is referred to you for judgment upon its substantial merit.

Dean James A. Mau

College of Arts \& Sciences

The thesis of Gretchen A. Brown is approved.

Zuis A. Escovar, Ph.D., Chair

William M. Kurtines, Ph.D.

Fernando Gonzalez-Reigosa,'Ph.D.

Date of Examination: December 16, 1982 
c Copyright by

Gretchen A. Brown

1982 
PERCEIVED AND ACTUAL SEX DIFFERENCES

IN ATTRIBUTIONAL STYLE FOR AFFILIATIVE BEHAVIOR by

Gretchen A. Brown

A thesis submitted in partial fulfillment of the requirements for the degree of

MASTER OF SCIENCE

in

PSYCHOLOGY

at

FLORIDA INTERNATIONAL UNIVERSITY

1982 


\section{ACKNOWLEDGEMENT}

I would like to gratefully acknowledge the assistance of Dr. Charles Carver of the University of Miami who allowed me access to the students in his subject pool; the undying financial and emotional support from my parents and family; and the support and guidance from my thesis committee. I would also like to give my special thanks to the chair of my committee, Dr. Luis A. Escovar, whose efforts in giving me support and guidance went above and beyond the call of duty. Working with Dr. Escovar allowed me to learn, by his example, the skills of a professional researcher, of which this thesis is proof, and the valuable lesson of the rewards gained from giving unselfishly of myself. To all of you, to Kathy Roland, my friend and typist, and my peers in this program, thank you for helping me to be myself and to do my best. In gratitude, I dedicate this thesis to you. 


\section{TABLE OF CONTENTS}

SECTION

PAGE

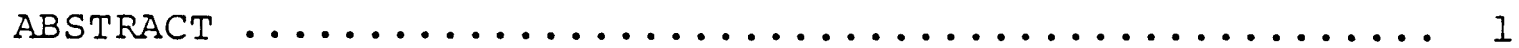

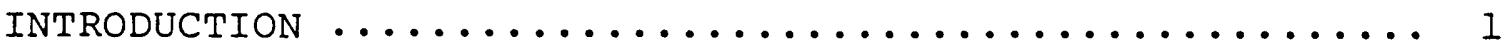

LEARNED HELPLESSNESS THEORY ....................... 2

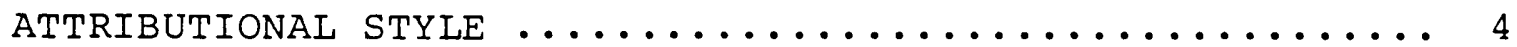

ATTRIBUTIONAL STYLE AND ACHIEVEMENT ............. 10

Achievement Orientation and Gender ......... 14

ATTRIBUTIONAL STYLE AND AFFILIATION ............ 21

Affiliative Orientation and Gender ......... 22

Affiliative Orientation and Perceived

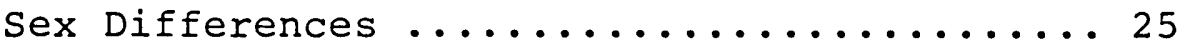

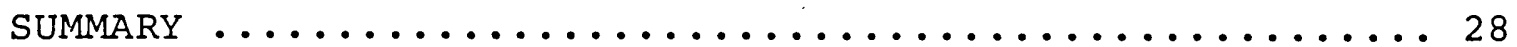

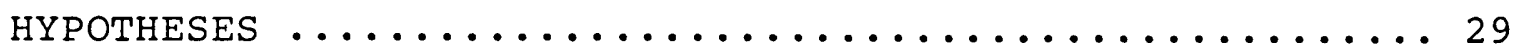

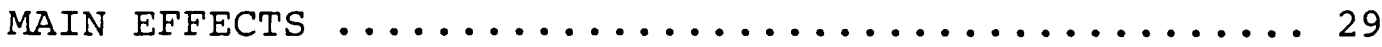

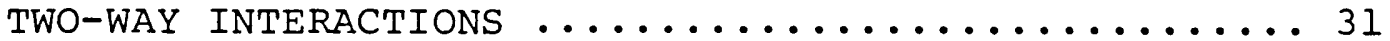

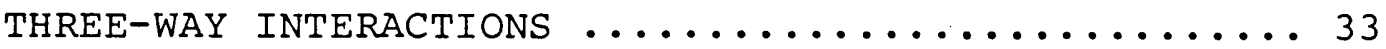

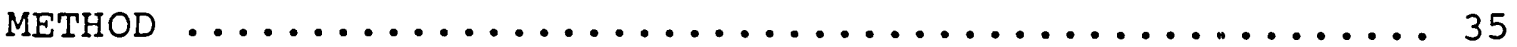

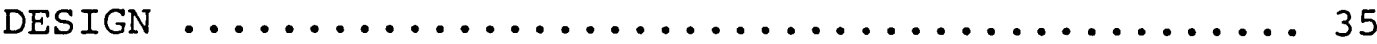

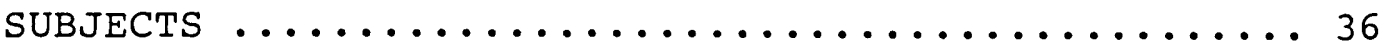

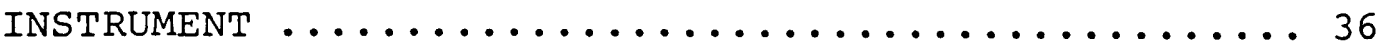

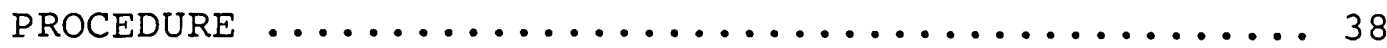

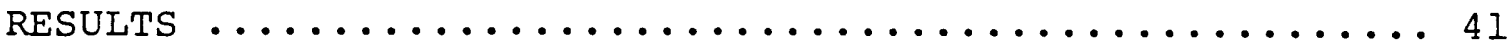

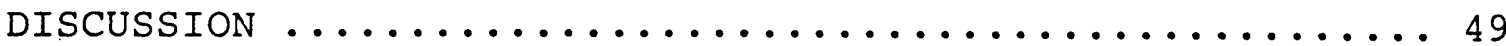

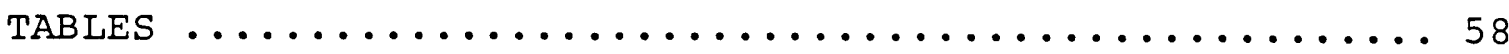




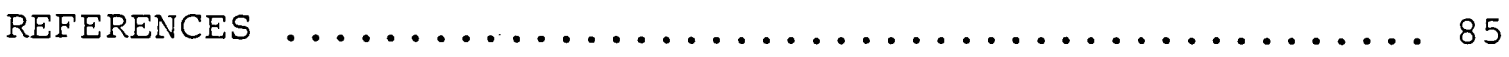

REFERENCE NOTES ............................ 84

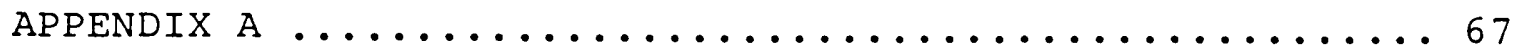

EBR-ASQ for Affiliative Behavior ..............68 


\section{List of Tables}

TABLE 1 Tabular Presentation of the 2(Sex) X 2(Perspective) X 2 (Outcome) Factorial Design

TABLE 2 Dependent Variables

TABLE 3 Means, Standard Deviations, Internal Consistency Coefficients, and Five week Test-Retest Reliability Coefficients for the EBR-ASQ Attributional Dimension

TABLE 4 Means, Standard Deviations, Internal Consistency and Standardized Item Coefficients for the EBR-ASQ Attributional Dimensions - Test Population

TABLE 5 Significance of Order Effects

TABLE 6 Sex, Perspective, and Outcome Means by Dimensions as Compared in the Main Effects Analyses

TABLE 7 Sex by Perspective, Sex by Outcome, and Perspective by Outcome Means by Dimensions as Compared in the Two-Way Interaction Analyses

TABLE 8 Sex by Perspective by Outcome Means by Dimensions as Compared in the Three-Way Interaction Analyses 
PERCEIVED AND ACTUAL SEX DIFFERENCES IN

ATTRIBUTIONAL STYLE FOR AFFILIATIVE BEHAVIOR

Attributional theory is among the most current and comprehensive of the cognitive-behavioral theories being developed and refined for the assessment and explanation of the motivational forces underlying human behavior. As such, it can be used in the examination of actual and perceived human sex differences. The objectives of the following proposal constitute a threefold extension of this theoretical logic by (1) reviewing the development of the concept of "attributional style", (2) demonstrating its applicability to affiliative behavior, and (3) documenting not only the existence of actual sex differences in attributional style but the perception of such differences for affiliative behavior as well.

To fulfill the first two objectives the development of the current attributional theory will be traced from the Abramson, Seligman, and Teasdale (1978) presentation of the reformulated learned helplessness model through Weiner's (1979) examination of attributional style as a motivational feature of achievement behavior to the application of attribution theory to affiliative behavior. To fulfill the third objective the evidence detailing the sex differences in attributional style will be reviewed within the framework of perception of sex appropriate behavior. Finally, a study will be designed to assess both actual and perceived sex differences in attributional style for affiliative behavior. 


\section{Learned Helplessness Theory}

The term "learned helplessness" was first coined by Overmier and Seligman in 1967 to explain the avoidanceresponse deficits produced in dogs exposed to inescapable shock. These dogs learned response-reinforcement independence (i.e., no response would effect the outcome). The direct result of such learning was nonexistent or retarded avoidance responding in later situations in which avoidance responding would have been effective. Furthermore, dogs so conditioned were difficult to retrain to exhibit normal avoidance behavior. These dogs learned to be helpless. Further studies, using a wide variety of species and different types of uncontrollable, aversive events, replicated these results (Seligman, 1975).

In 1975 Miller and Seligman developed the original learned helplessness theory of depression in humans. In brief, this theory proposed that a belief in response-outcome independence was a central feature of reactive depression. In a study designed to test this theory it was hypothesized that depressed college students, as compared to their nondepressed peers, would exhibit performance deficits on an experimental task after exposure to uncontrollable, aversive stimuli. The results confirmed this hypothesis (Miller \& Seligman, 1975). However, inconsistent data were generated by following investigations and Costello (1978), in his extensive review of this material, indicated that major theoretical refinements were necessary if the learned helplessness theory of depression in humans was to remain viable. 
In that same year Abramson, et al. (1978) published their reformulated learned helplessness model. The accumulated evidence suggested two distinct types of learned helplessness: universal and personal. In universal helplessness the individual perceives the cause of the aversive stimuli to be uncontrollable not only by the self but by all relevent others in the same situation. The relationship between the response and the reinforcement is perceived as universally independent. Specific reinforcement contingent responding may be impaired but feelings of lowered self-esteem and depression are not part of the cognitive-affective consequences. Personal helplessness, however, does induce lowered self-esteem and depression. In personal helplessness the response-reinforcement independence is perceived as being relevant only to the self while significant others are perceived as having the power of response-reinforcement dependence. Reinforcement contingent responding is impaired in a more generalized fashion as a result of the lowered self-esteem, depressive feelings, and the perception of personal responsibility for the response-reinforcement independence. The major theoretical contribution of the Abramson, et al. (1978) reformulation is the simple explanation of the variations of learned helplessness, the causal factors involved, and the conditions under which it may generalize across situations. The key feature of the reformulated learned helplessness model that provides a foundation for most current research on attributional style is the specification of the roles of certain causal characteristics (i.e., controllability, 
stability, etc.) in the production of affective consequences. To illustrate, consider the differences between personal and universal helplessness which either bring about or fail to bring about the deficits in self-esteem that lead to depression. The characteristics of the uncontrollability of the cause by the actor is perceived to exist in both personal and universal helplessness. The perception of uncontrollability produces feelings of helplessness. In universal helplessness the locus of this uncontrollability is perceived to be external to the actor. This external attribution allows the actor to escape any personal responsibility for failure (i.e., "I may not be able to control this outcome, but neither can anyone else."). Universal helplessness, then, produces situation specific response impairment without creating deficits in self-esteem leading to depression. In personal helplessness, however, the locus of the uncontrollability of the cause is perceived as internal to the actor. This internal locus forces the actor to assume personal responsibility for any failure (i.e., "I can't control the outcome, but some/everyone else can."). This assumption of personal responsibility for failure leads to deficits in self-esteem and depression. The resultant response impairment may then generalize across situations where response contingent outcomes exist.

\section{Attributional Style}

Attributional theory focuses upon two components of causal attributions: (1) the habitual use of certain types 
of causes to explain events and (2) the categorization of causal attributions by their general characteristics. All events experienced by an individual are subject to cognitive processing. Determining explanations about the perceived causes(s) is part of this processing. A causal attribution, then, is the placement or definition of cause(s) of an event experienced, either directly or indirectly, by an individual. Furthermore, causes can be rated along a limited number of dimensions regarding the degree to which they possess certain characteristics. Individuals, over time, tend to habitually choose causes with the same or similar characteristics. This recurrent pattern of causal preference is termed "attributional style". The delineation of the causal characteristic dimensions forms the foundation for the assessment of attributional styles.

There are two orientations and at least three general causal characteristic dimensions. The two orientations are (1) the attributors orientation (self versus another) and (2) the outcome orientation (success versus failure). The three general causal characteristic dimensions are (1) the locus of causality (internal versus external), (2) the degree of causal controllability (controllable versus uncontrollable), and (3) the degree of causal stability (stable versus unstable). The attributor and outcome orientations are true dichotomies while the causal characteristic dimensions represent continua. A cause is rated to determine its orientations and the degree to which it possesses one or the other of the characteristics along each dimension. 
The attributors' orientation, or the self versus other (s-O), indicates who is the subject of the attribution (i.e., is the attribution being made about an event involving the self or an event involving another?). The s-o perspective represents both the social comparison process and the focus of the attributors attention (Arkin \& Duvall, 1975; Nisbett, Caputo, Legant, \& Mereck, 1973). Individuals making causal attributions about their own behavior tend to focus upon environmental constraints as intervening factors. The causal factors of the behavior of others, however, are habitually attributed to the dispositional characteristics of the actor. The causes of this differential pattern have not been fully explored but the pattern remains consistent (Arkin \& Duvall, 1975; Deaux \& Farris, 1977; Miller, 1976; Nisbett, et al., 1973).

The outcome orientation, or success versus failure (S-F), concerns the degree to which an event is perceived as a success or a failure. The S-F orientation is indicative of both the degree of threat an individual feels and the amount of responsibility s/he is willing to accept for the outcome. Both common sense and empirical data (Arkin, Appleman, \& Burger, 1980; Kuiper, 1978; Miller, 1976; Sobel, 1974; Struefert \& Struefert, 1969) support the thesis that failure outcomes are ego threatening and successful outcomes are ego enhancing. Furthermore, individuals take more personal responsibility for successful outcomes (Arkin, et al., 1980; Kuiper, 1978; Miller, 1976; Sobel, 1974; Struefert \& Struefert, 1969). 
Consistent with the Abramson, et al. (1978) learned helplessness model, however, depressed individuals take more personal responsibility for failure (Golin, Sweeney, \& Schaeffer, 1981; Hammen \& Cochran, 1981; Klein, Morse, \& Seligman, 1976; Rizley, 1978).

The delineation of the causal dimensions is drawn from the amended attributional analysis of achievement behavior performed by Weiner (1979). These dimensions specify the causal characteristics used in attributional style.

The locus of causality (internal versus external) dimension (I-E) specifies the locus of the cause, regardless of whether the self or another is the actor. The locus or location is internal when some characteristic or behavior within the actor is perceived as the cause of an event. The internal locus of uncontrollability in the personally helpless attributional style (Abramson, et al., 1978), in which some characteristic or behavior internal to the actor (e.g., lack of ability) is perceived as causative of an outcome, exemplifies this concept. The locus of the cause is external when some characteristic of the environment or person other than the actor is perceived as the cause of an event. The external locus of uncontrollability in the universally helpless attributional style, in which some characteristic or action external to the actor (e.g., the phases of the moon or an act of God) is perceived as causative of an outcome, exemplifies this concept. The affective consequences of habitually choosing internal or external causes 
are well documented. Choosing internal causes for success and external causes for failure is an ego enhancing attributional style (Arkin, et al., 1980; Kuiper, 1978; Miller, 1976; Sobel, 1974; Struefert \& Streufert, 1969). Habitually making internal attributions for failure and external attributions for success is an ego depreciative and depressive attributional style (Golin, et al., 1981; Hammen \& Cochran, 1981; Klein, et al., 1976; Rizley, 1978).

The controllability (controllable versus uncontrollable) dimension (C-UC) specifies the degree of perceived control the actor has over the cause (Weiner, 1979), regardless of whether the self or another is the actor. The cause of an event is controllable if the actor is perceived as having instrumental control over it (i.e., self or object manipulation or the power of persuasion). This conforms to the Miller and Seligman (1975) concept of response-outcome dependence. The cause of an event is uncontrollable if the actor is perceived as having no instrumental control over it. This conforms to the Miller and Seligman (1975) concept of response-outcome independence. The perception of responseoutcome independence or causal uncontrollability is that causal characteristic which is common to, and induces, both universal and personal helplessness and the resultant reinforcement-contingent response deficit (Abramson, et al, 1978; Miller \& Seligman, 1975; Overmeir \& Seligman, 1967). The stability (stable versus unstable) dimension (S-US) is the final causal dimension. The S-US dimension specifies 
the degree of perceived stability the cause possesses over time. The cause of an event is stable if it is perceived as continuous or constant through time or it is recurrent in a regular and/or predictable manner (e.g., the earth is always round or the regularity of the changing seasons). The cause of an event is unstable if it is perceived as rare or recurrent in an infrequent, irregular, and/or unpredictable manner (e.g., an earthquake in Florida or the behavior of an unknown other) (Weiner, 1979). The concept of predictability links stability with controllability. Causes that are either or both stable and/or controllable are predictable. Causes that are either or both unstable and/or controllable may not be predictable. The stability dimension modulated the affects produced by the other dimensions. To illustrate this concept, consider the ego enhancing attributional style. The positive affect is much greater if success is attributed to an internal, stable cause (e.g., ability) than if it is attributed to an internal, unstable cause (e.g., good mood). This modulation applies to the ego depreciative, depressive attributional style as well. The negative affect generated by an internal, stable cause for failure (e.g., lack of ability) is much greater than for an internal, unstable cause (e.g., bad mood).

Every causal attribution can be made from two different perspectives and rated on three dimensions. Therefore, any causal attribution can be about either the self or another as the actor; and a success or a failure. The event can be attributed to a cause that is either internal or external to 
the actor, controllable or uncontrollable by the actor, and stable or unstable through time.

This section has described the two perspectives from which attributions can be made and three of the most important dimensions used in the attribution process. The combination of these perspectives and dimensions provide a set of attributional categories which have been used to study differential patterns of academic achievement (Weiner, 1979). The next section reviews the literature on attributional style and achievement behavior.

Attributional Style and Achievement

The bulk of the literature on causal attributions and attributional style focuses upon achievement behavior; the role of causal attributions in this area is now well documented (Dweck, Goetz, \& Strauss, 1980; Weiner, 1979). However, during the second half of the 1970's educational psychologists were intrigued with the concept of learned helplessness (Abramson, et al, 1978; Miller \& Seligman, 1975; Overmier \& Seligman, 1967). Learned helplessness theory offered a plausible explanation for the differential achievement patterns exhibited by children with roughly equivalent academic potential and ability. A variety of investigations were undertaken to assess the causal attributions generated in response to success and failure in achievement orientea situations. The purpose of these studies was to determine if those causal attributions did, indeed, affect academic motivation and performance. Two notable and 
relatively stable patterns of results emerged: (1) different causal attributions were generated by mastery oriented versus helpless children and (2) a relatively stable correlation existed between achievement orientation and gender.

The literature detailing the affective and performance consequences of different causal attributions generated by mastery oriented versus helpless children and college students is best illustrated by a few rigorous and comprehensive studies. In 1965 Crandall, Katkovski, and Crandall demonstrated that differential causal attributions generated for success and failure as measured by the IAR, Intellectual Achievement Responsibility Questionnaire, were highly correlated with differing levels of achievement motivation and performance in 923 elementary through high school students. A belief in greater internal responsibility for achievement outcomes (termed internal reinforcement responsibility) was highly and consistently correlated with increased levels of achievement motivation and performance (Crandall, et al., 1965).

Kukla (1972) substantiated and extended the Crandall, et al., (1965) findings by soliciting the causal attributions for both success and failure achievement outcomes generated by high, intermediate, and low achieving college students. Consistent with previous data (Crandall, et al., 1965) high achievers took more personal responsibility for both success and failure and cited ability and effort as the major causal agents. Furthermore, when instructed to attribute performance 
to ability and effort, high achievers exhibited enhanced performance on an experimental task. Intermediate achievers consistently chose ability as the main causal agent in success and bad luck, in failure. Low achievers made a variety of causal attributions for both success and failure. Instructions to attribute outcomes to ability and effort did little to change either performance or causal preference in this group. A variety of explanations for this final result were explored by Kukla (1972), however, the learned helplessness model provides the most plausible framework for understanding the generalized, unchanging poor performance of the low achieving group.

The concepts of internal reinforcement responsibility (Crandall, et at., 1965) and the learned helplessness explanation of Kukla's (1972) low achievers were drawn together by Dweck and Repucci (1973) in their investigation of the relationship between internal reinforcement responsibility and both mastery and helpless achievement behaviors. Again, the belief in internal reinforcement responsibility and greater achievement motivation, as measured by persistence and performance, were highly correlated with the choice of effort as the major causal agent in both success and failure. Learned helpless achievement behavior and little or no acceptance of personal responsibility for outcomes were correlated inconsistently with either the ascription of ability as the major causal agent for success and/or luck/task 
difficulty as the major causal agent(s) for success and failure outcomes.

Diener and Dweck (1978), however, documented consistent causal attributions generated by helpless children in failure-only achievement situations. Soliciting causal attributions during, rather than before and/or after, failure-only achievement tasks uncovered several unique attributional patterns. Consistent with previous findings (Crandall, et al., 1965; Dweck \& Repucci, 1973; Kukla, 1972), mastery oriented children exhibited persistent or enhanced performance after failure. Learned helpless children did not. Task concurrent verbalizations by helpless children focused upon lack of ability as the main causal agent. Surprisingly, mastery oriented children did not focus upon a causal agent but engaged, instead, in self-monitoring and self-instructing verbalizations. Furthermore, mastery oriented children engaged in hypothesis testing and strategy changing which enhanced their performance. Helpless children decreased persistence or reverted to using easier and less effective strategies. These results document a process whereby certain causal attributional patterns generated during failure are linked to behavioral changes conducive to enhanced or decreased performance (Diener \& Dweck, 1978). From the documentation provided (Crandall, et al., 1965; Diener \& Dweck, 1978; Dweck \& Repucci, 1973; Kukla, 1972), several consistent attributional and behavioral patterns begin to crystalize. Learned helpless achievement behavior 
is correlated with causal attributions for failure to ability, or the lack thereof, (i.e., internal, uncontrollable, stable causal attributions) and attributions for success to luck/task difficulty (i.e., external, uncontrollable causal attributions). This pattern, then, emerges as a learned helpless, ego depreciative achievement attributional style. The mastery oriented, ego enhancing achievement attributional style, however, emerges as a pattern of belief in personal responsibility for both success and failure coupled with causal attributions for both types of outcomes to effort, or the lack thereof (i.e., internal, controllable causal attributions) with some attributions for success to ability (i.e., internal, uncontrollable, stable causal attributions). These investigations were primarily concerned with discovering the relationship between patterns of causal attribution generation, achievement motivation, and performance. The association between achievement orientation and gender was not the main focus and was either not examined or found not as highly significant as other results in post hoc analyses (Crandall, et al., 1965; Diener \& Dweck, 1978; Dweck \& Repucci, 1973; Kukla, 1972). However, a clear and stable correlation between achievement orientation and gender is well documented. The next section will examine the documented relationship between specific achievement attributional styles and gender.

Achievement Orientation and Gender

The literature detailing the nature and extent of the relationship between achievement orientation and gender is 
best illustrated by a few rigorous and comprehensive studies. Building upon the previous research on achievement orientation and attributional style, Nicholls (1975) uncovered a distinct association between achievement orientation and gender. Elementary school boys demonstrated a more mastery oriented attributional style (as documented by previous findings) and persistently cited ability as the main causal factor in success with bad luck as the main causal factor in failure. The girls, on the other hand, evidenced a more self depreciatory, helpless attributional style and cited lack of ability, repeatedly, as the main causal agent in failure. Consistent with this data boys evidenced a higher expectancy for future success than did girls (Nicholls, $1975)$.

Dweck and Gilliard (1975) replicated and extended the findings. However, before examining the attributional patterns of boys and girls, it was discovered that the process of soliciting causal attributions and expectancies for future success and failure either or both before and/or after task performance created increased perceptions of evaluative pressure such that the more frequent the causal and expectancy solicitations the greater the feelings of evaluative pressure. This finding enabled the experimenters to systematically vary the levels of perceived evaluative pressure. Boys and girls again differed in their attributional styles with boys preferring a more self enhancing, mastery orientation, and girls preferred a more 
self depreciatory, helpless orientation. Causal ascription by boys and girls for success and failure substantiated Nicholls' (1975) findings. Furthermore, boys evidenced a greater expectancy for future success than did girls. An increased frequency of solicitation of causal and expectancy verbalizations created differential patterns of responding in boys versus girls. The girls exhibited a downward trend in both expectancies and performance citing increased feelings of evaluative pressure. Boys evidenced the opposite trend citing increased feelings of challenge.

Together the Nicholls (1975) and Dweck and Gilliard (1975) studies provide evidence of a strong correlation between achievement orientation and gender. Moreover, they documented the relationship between attributional style, expectancy for future success, and actual performance. An ego enhancing attributional style, demonstrated more frequently by boys, is highly correlated with mastery achievement orientation, high expectancy for future success, and better performance after failure. The ego depreciative attributional style, demonstrated more frequently by girls, is highly correlated with helpless achievement orientation, low expectancy for future success, and poorer performance after failure (Dweck \& Gilliard, 1975; Nicholls, 1975). These attributional patterns have been further substantiated by Dweck and her colleagues in a series of investigations designed to ferret out possible causative factors.

In the first of this series, Dweck and Bush (1976) again substantiated the association between attributional style and 
gender. They attempted to link this pattern with characteristics of the evaluating agent. Male and female adult and peer evaluators produced differential patterns of causal attribution generation in boys versus girls. Failure feedback from female, adult evaluators produced lack of ability attributions and performance deficits in girls, but lack of effort attributions and enhanced performance in boys. Similar feedback from female peers produced lack of effort attributions and enhanced performance in girls while feedback from male peers produced lack of ability attributions and performance deficits in boys. These results indicated that the helplessness response to negative feedback was, indeed, agent specific. Dweck and her colleagues designed two further studies assessing the qualities of evaluative feedback in the classroom to uncover the techniques employed by adult evaluators responsible for these differences in girls and boys.

In the first section of this two part study Dweck, Davidson, Nelson, and Enna (1978) examined the positive and negative feedback delivered to boys and girls by female, adult evaluators. Female evaluators were studied exclusively because of the striking results of the Dweck and Bush (1976) investigation, and because in reality the vast majority of elementary and high school teachers are women. Dweck, et al. (1978) documented that the type and focus of feedback delivered to boys versus girls was markedly different. The absolute amounts of positive feedback were equivalent, however, 
boys received greater amounts of negative evaluations. The positive feedback delivered to boys focused upon ability while similar feedback to girls focused upon expenditure of effort. The focus of the negative feedback followed exactly the opposite pattern. Moreover, negative evaluations directed towards the boys was extensive but diffuse, focusing more upon misconduct and rule breaking behavior. Similar feedback delivered to the girls was infrequent and highly task specific, focusing upon lack of ability attributions generated by the evaluator. Dweck, et al. (1978) reasoned that through extensive exposure boys become habituated to such negative feedback, thus enabling them to discount its importance. This allows boys less affective responsiveness. However, girls experience greater affective consequences because of the infrequency and specific lack of ability attributional focus of negative evaluations.

The purpose of the second section of this study was to determine if the differential reinforcement patterns documented in part one were solely responsible for the sex differences in attributional style and achievement behavior (Dweck, et al., 1978). Two failure feedback "scripts" were created: a girl script, consisting of failure feedback typical of that delivered to girls in part one of the study. A boy script was created in the same way. Each script was delivered to a gender mixed group of children by a male evaluator. Both boys and girls within each group received equal feedback. Failure feedback only was delivered 
and causal attributions were solicited after each task performance. Both boys and girls in the "girl condition" showed performance deficits and focused upon lack of ability as the causal agent. The "boy condition" provoked no performance deficits and the causal attributions generated focused upon lack of effort. Dweck, et al. (1978) concluded that "These two studies, taken together, demonstrate that the pattern of evaluative feedback given to boys and girls in the classroom can result directly in the girls' greater tendency to view failure as indicative of their level of ability" (p. 274) .

Dweck, Goetz, and Strauss (1980) designed the final, two part study in this series to assess the extent to which the reinforcement delivered to boys and girls created internalized patterns of causal attribution generation which generalized, in the form of expectancies, to new achievement situations. The first section consisted of a five trial controlled task. In the first four trials failure feedback was delivered exclusively. On the fifth trial the condition was manipulated in one of four ways: (1) a new task, (2) a new evaluator, (3) both, or (4) neither. Expectancies were solicited before each trial. From trials one to four expectancies for success declined steadily. This effect was more pronounced for the girls. When both the task and the evaluator remained unchanged, expectancies continued to decline. When the evaluator changed boys' expectancies rose while girls' continued to decline. When the task and 
the evaluator changed expectancies rose for both the boys and the girls, although this pattern was significantly more pronounced for the boys. Overall, the initial expectancies and the level of expectancy recovery was consistently greater for the boys. These results indicate that the pattern of making internal, uncontrollable, stable causal attributions for failure to lack of ability, that pattern which is reinforced in girls, does indeed, generalize to new situations in the form of lowered expectancies for future success. To determine if this pattern reflected an academic reality, a naturalistic analogue to this controlled study was designed.

The second section solicited expectancies for success for a new school year, both before the start of the year and again after the first administration of evaluative feedback (i.e., the first report card). The expectancy patterns documented in the first phase of this study were substantiated. When previous evaluative feedback for failure focused upon lack of effort expectancies were high both before and after negative feedback. The girls, then, had lower expectancies and higher grades than the boys. It is interesting to note that the higher grades for the girls did not increase their expectancies but did raise the criterion for perceived success. Dweck, et al. (1980) concluded "...that causal attributions are critical in the generalization of failure experiences to new situations." (p. 451). Moreover, 
internal, uncontrollable, stable attributions to lack of ability for failure are reinforced in girls to the extent that "...failure leads them to perceive themselves as lacking in general ability, not merely an ability that is specific to the task on which they failed... indeed, that one is intellectually deficient." (Dweck, et al., 1980, p. 451).

The evidence thus demonstrates the importance of causal attributions and attributional style in achievement motivation, expectancy, and performance. Certain attributional styles enhance or deter adequate performance. Furthermore, specific patterns of causal attribution generation are reinforced differentially in girls versus boys. This creates different patterns of responding according to gender. This, in part, accounts for the different types of achievement behavior exhibited by males and females in and out of the classroom. Attributional style and Affiliation

Achievement is, however, only one behavioral domain. Affiliation, or the interpersonal relationships domain, represents another arena in which attributional style plays a significant role. There is a paucity of data on the role of attributional style in affiliation. The bulk of past literature deals with achievement behavior and the classroom experience. However important these domains may be, interpersonal relationships have an equal if not greater impact and possibly are more salient to most individuals because of the role of affiliation in every day activity. The information available suggests a parallel juxtaposition both in patterns of preference and functional consequences 
between affiliation and achievement causal ascription

(Peterson, Semmel, von Baeyer, Abramson, Metalsky, \& Seligman, Note 2). It has been demonstrated that the learned helpless, depressive attributional style is as applicable to affiliative behavior as it is to achievement (Abramson, et al., 1978; Seligman, Abramson, Semmel \& von Baeyer, 1979). The performance deficits created by such causal preferences show up in affiliative behavior as depression, with its concomittant withdrawal and deficited and/or regressive responding. What literature is currently available focuses upon two issues:

(1) the propensity for women to exhibit and thus suffer from the consequences of a depressive attributional style and

(2) the tendency for individuals to ascribe different causal agents as responsible for the actions of others, versus actions of the self, especially others of the opposite sex

\section{Affiliative Orientation and Gender}

In light of the documentation presented on achievement attributional styles several studies will be examined detailing the affiliative orientations of males and females. The role of affiliation in mental health is paramount. To maintain affiliative ties and thus enhance mental health an individual's behavior must conform, at least to some degree, to socially prescribed norms. These norms are best understood within the context of sex-role stereotypes. Behavior excessively deviant from such stereotypes is condemned and 
penalties of loss of affiliative support and social rejection may be incurred (Costrich, Feinstein, Kidder, Marecek, \& Pascale, 1975). Fear of achievement success in females and fear of achievement failure in males are affective consequences of contemplated and/or actual sex-role violations. Females evidence an increased fear of social rejection by their affiliative support group following achievement success (Feather \& Simon, 1973). Furthermore, both males and females make external, uncontrollable attributions for feared outcomes, possibly in an attempt to "disown" responsibility for such undesirable outcomes. The Costrich, et al. (1975) and Feather and Simon (1973) studies give support to the idea that sex appropriate behavior is different for males and females. The list of stereotypic behaviors appropriate for each sex is lengthly, however, a partial list indicates the degree to which these behaviors diverge from each other and coincide with previously documented achievement and affiliative behaviors and causal attributions. Female sex appropriate behaviors include passivity, dependence, emotionality, non-competitiveness, not being logical, incompetence, indecisiveness, lack of confidence, unambitiousness, nurturance, etc. Male sex appropriate behaviors are exactly opposite those appropriate for females (Broverman, Broverman, Clarkson, Rosenkrantz, \& Vogel, 1970). Reinforcement of sex-role stereotypes can and does predispose males towards a greater success orientation and ego enhancing attributional style. 
Affiliative behavior, however, is female sex-role appropriate and is reinforced as necessary for the nurturant role. As such, affiliation becomes the female analogue to achievement behavior for males. The ego depreciatory attributional style reinforced in females to explain achievement outcomes is reinforced, but to a lesser degree, to explain affiliative outcomes. The consequences of the learned helpless attributional style are moderated but not completely extinguished by the relative importance of affiliation in stereotypically feminine behaviors. This generally helpless orientation is, in part, substantiated by the greater incidence of depression among women (Radloff \& Monroe, 1978; Stein \& Bailey, 1973).

Opposing the learned helpless attributional styles reinforced in females are the ego enhancing attributional styles reinforced in males. Achievement success is considered male sex appropriate, hence, it is emphasized over affiliative success by males (Broverman, et al., 1970). The affective reactions, and causal attributions generated in response, to comtemplated and/or actual achievement failure by males in the fear of success and failure studies (Costrich, et al., 1975; Feather \& Simon, 1973) substantiated this contention. Moreover, the most success oriented, ego enhancing attributional styles, reinforced in males for achievement outcomes, are generalized over to and reinforced for affiliative outcomes (Feather \& Simon, 1978; Stein \& Bailey, 1973). This parallels the generalization of attributional styles that occurs with 
females. The relative lower priority of affiliation in male sex appropriate behavior serves to moderate the extreme exhibition of the ego enhancing attributional style, making it less apparent in causal attributions made by males in response to affiliative outcomes. The effects of the relative priority of affiliation in sex appropriate behaviors, then, serves to bring the divergent attributional styles, evidenced in achievement behavior, into closer proximity with each other for affiliative behavior. The result is gender specific affiliative attributions that are less divergent and less extreme than gender specific achievement attributions, while still resembling them (Hanusa, 1975).

\section{Affiliative Orientation and Perceived Sex Differences}

The actual sex differences in affiliative attributions are of a smaller magnitude than the sex differences in achievement attributions. However, the perception of such sex differences are an entirely separate subject. The previous discussion of Weiner's (1979) attributional orientations and dimensions focused, at one point, upon the differences in causal attributions made for the actions of the self versus the actions of another. This particular phenomenon was deemed important enough to merit its inclusion as an attributor's orientation. Reviewing this topic in brief, there are two principal factors contained in the self-other orientation. The first factor is the social comparison process and the second factor is the attributor's focus of attention. The combined effect of both 
factors is the tendency to consider environmental constraints in attributing the causes for the behavior of the self and dispositional causes for the behavior of another (Arkin \& Duval1, 1975; Deaux \& Farris, 1977; Miller, 1976; Nisbett, et al., 1973). Furthermore, the affects generated by this phenomenon follow a distinct, stable, gender specific pattern.

There is ample documentation that for sex appropriate, sex inappropriate, and neutral task outcomes there is a clear-cut, stable pattern for both males and females to attribute success by a female actor to an external, uncontrollable, unstable cause (i.e., good luck), failure of a female actor to an internal, uncontrollable, stable cause (i.e., lack of ability), success by a male actor to an internal, uncontrollable, stable cause (i.e., ability), and failure of a male actor to an external, uncontrollable, unstable cause (i.e., bad luck). Furthermore, when internal, controllable (i.e., expenditure of effort) attributions were made it was consistently in terms of female success and male failure; when external, uncontrollable, stable (i.e., task difficulty or ease) attributions were made it was in response to both female success (task ease) and failure (task difficulty) and male failure (task difficulty (Deaux \& Emswiller, 1974; Deaux \& Farris, 1977; Feather \& Simon, 1975; Yarkin, Town, \& Wallston, 1982). This differential perception of males and females appears to be patterned after the actual causal 
attributions generated by males ard females for achievement outcomes; this indicates a general consensus as to the causes of gender specific outcomes as well as for gender specific behaviors. These perceptions are consistent and generalize over sex appropriate, sex inappropriate, and neutral tasks for both males and females, that is, for both achievement and affiliative tasks. Therefore, documented perceptions of sex differences in causal attributions for affiliative outcomes are actually greater than the true sex differences for affiliative outcomes.

Although there are many and great differences between individuals there are, consistent with previous documentation, what can be labeled gender-typical, affiliative attributional styles. For males the gender-typical, affiliative attributional style is similar to the achievement ego enhancing attributional style. That is, males make internal, uncontrollable, stable and internal, controllable attributions to ability and effort for affiliative success and internal, controllable and external, uncontrollable, unstable attributions to effort and luck for affiliative failure. The extreme nature of this attributional style, extant in achievement behavior however, is mitigated to some degree by the relative lower priority of affiliative behavior for males. For females the gender-typical, affiliative attributional style is similar to the achievement ego depreciative attributional style. That is, females make external, uncontrollable, unstable and internal, controllable 
attributions to luck and effort for affiliative success anả internal, uncontrollable, stable and internal, controllable attributions to lack of ability and effort for affiliative failure. The extreme nature of this attributional style, extant in achievement behavior, however is mitigated to some degree by the relative higher priority of affiliative behavior for females.

This section has reviewed the existing evidence concerning affiliation, attributional style, and the relevance of gender to this area. It has outlined a logical argument consistent with available data. The following section will provide an overview and summarize the major points covered thus far.

\section{Summary}

The documentation in the literature demonstrates that causal attributions generated in response to success and failure outcomes can and do affect both expectancy and performance. The roles of two attributional styles have been studied in achievement behavior. The ego depreciative attributional style, reinforced in and exhibited more frequently by females, leads to lower expectancies and poorer performance especially after failure. The mastery oriented, ego enhancing attributional style, reinforced in and exhibited more frequently by males, leads to higher expectancies and better performance even after failure. There is a paucity of information concerning the role of 
attributional style in affiliation but the available data indicates that causal attributions generated in response to achievement outcomes parallel causal attributions generated in response to affiliative outcomes. The gender specific attributional patterns and their functional consequences evident in achievement parallel those evident in affiliation. However, the extreme nature of these attributional styles are mitigated, to some degree, by sex-role stereotypes and the sex appropriateness of achievement and affiliative behaviors, thereby making them more similar to each other for affiliative behavior. Furthermore, perceived sex differences in affiliative attributional styles appear more like the actual sex differences in achievement attributional styles. Thus, perceived sex differences in affiliative attributional styles are greater than the actual affiliative attributional sex differences. In accord with the evidence presented and this line of reasoning several hypotheses will be asserted.

\author{
HYPOTHESES
}

\title{
Main Effects
}

1. A. A significant main effect of the sex factor is expected on the locus of causality dimension, with mean scores indicating that overall males perceive greater causal internality than do females;

B. A significant main effect of the sex factor is expected on the stability dimension, with mean 
scores indicating that overall males perceive greater causal stability than do females;

C. A significant main effect of the sex factor is expected on the controllability dimension, with mean scores indicating that overall males perceive greater causal controllability than do females.

2. A. A significant main effect of the Perspective factor is expected on the locus of causality dimension, with mean scores indicating that overall individuals perceive greater causal internality for themselves than for members of the opposite sex;

B. A significant main effect of the perspective factor is expected on the stability dimension, with mean scores indicating that overall individuals perceive greater causal stability for themselves than for members of the opposite sex;

C. A significant main effect of the Perspective factor is expected on the controllability dimension, with mean scores indicating that overall individuals perceive greater causal controllability for themselves than for members of the opposite sex.

3. A. A significant main effect of the Outcome factor is expected on the locus of causality dimension, with mean scores indicating that overall individuals perceive greater causal internality for success than for failure;

B. A significant main effect of the Outcome factor is expected on the stability dimension, with mean 
scores indicating that overall individuals

perceive greater causal stability for success

than for failure;

C. A significant main effect of the outcome factor is expected on the controllability dimension, with mean socres indicating that overall individuals perceive greater causal controllability for success than for failure.

\section{Two-Way Interactions}

4. A. A significant Sex by Perspective interaction is expected on the locus of causality dimension, with mean scores indicating that in the self perspective males perceive greater causal internality than do females, and that in the opposite sex perspective females perceive greater causal internality than do males;

B. A significant Sex by Perspective interaction is expected on the stability dimension, with mean scores indicating that in the self perspective males perceive greater causal stability than do females, and that in the opposite sex perspective females perceive greater causal stability than do males;

C. A significant sex by Perspective interaction is expected on the controllability dimension, with mean scores indicating that in the self perspective males perceive greater causal controllability than 
do females, and that in the opposite sex perspective females perceive greater causal controllability than do males.

5. A. A significant sex by outcome interaction is expected on the locus of causality dimension, with mean scores indicating that males perceive greater causal internality for success than do females, and that females perceive greater causal internality for failure than do males;

B. A significant sex by Outcome interaction is expected on the stability dimension, with mean socres indicating males perceive greater causal stability for success than do females, and that females perceive greater causal stability for failure than do males;

C. A significant sex by Outcome interaction is expected on the controllability dimension, with mean scores indicating that males perceive greater causal controllability for success than do females, and that females perceive greater causal controllability for failure than do males.

6. A. A significant Perspective by Outcome interaction is expected on the locus of causality dimension, with mean scores indicating that in the self perspective individuals perceive greater causal internality for success than for failure, and that in the opposite sex perspective individuals perceive greater causal internality for failure than for success; 
B. A significant Perspective by Outcome interaction is expected on the stability dimension, with mean scores indicating that in the self perspective individuals perceive greater causal stability for success than for failure, and that in the opposite sex perspective individuals perceive greater causal stability for failure than for success;

C. A significant Perspective by outcome interaction is expected on the controllability dimension, with mean scores indicating that in the self perspective individuals perceive greater causal controllability for success than for failure, and that in the opposite sex perspective individuals perceive greater causal controllability for failure than for success.

Three-Way Interactions

7. A. A significant Sex by Perspective by Outcome interaction is expected on the locus of causality dimension, with mean scores indicating that in the self perspective males perceive greater causal internality for success than do females, and females perceive greater causal internality for failure than do males, and that in the opposite sex perspective females perceive greater causal internality for success than do males, and males perceive greater causal internality for failure than do females; 
B. A significant Sex by Perspective by outcome interaction is expected on the stability dimension, with mean scores indicating that in the self perspective males perceive greater causal stability for success than do females, and females perceive greater causal stability for failure than do males, and that in the opposite sex perspective females perceive greater causal stability for success than do males, and males perceive greater causal stability for failure than do females;

C. A significant Sex by Perspective by Outcome interaction is expected on the controllability dimension, with mean scores indicating that in the self perspective males perceive greater causal controllability for success than do females, and females perceive greater causal controllability for failure than do males, and that in the opposite sex perspective females perceive greater causal controllability for success than do males, and males perceive greater causal controllability for failure than do females. 
METHOD

Design

This study utilized a $2 \times 2 \times 2$, three factor, multivariate, repeated measures design. The first factor, a between subjects factor, was the sex of the subject. Data was gathered from approximately the same number of male and female subjects. The second factor, a within subjects factor, was the perspective from which the questionnaire was answered; answering for the self, and as if one was a member of the opposite sex. It is an independent variable and all subjects answered the questionnaire from both perspectives. The third factor, a within subjects factor, was the outcome orientation; success and failure. All subjects answered items in both orientations. Each attributional dimension (i.e., locus of causality, stability, and controllability) was assessed in each of the four perspective by outcome orientation cells (i.e., success for the self, failure for the self, success for the opposite sex, and failure for the opposite sex). These attributional dimensions comprised the dependent variables.

\section{INSERT TABLE I ABOUT HERE}

The data collected from the questionnaires was analyzed using a multivariate analysis of variance (MANOVA) statistical design from the BMDP. $4 \mathrm{v}$ computer package (See Table 1). 
Subjects

The subjects in this study were 107 Florida International University and University of Miami undergraduates, psychology student volunteers. Only Anglo students were recruited due to the possible confounding influence of ethnicity. The test population of 107 students had a mean age of 20.5 years. of the total sample 55 were males with a mean age of 19.5 years and 52 were females with a mean age of 21.5 years.

\section{Instrument}

The EBR-ASQ for Affiliative Behavior was developed at Florida International University by Escovar, Brown, and Rodriguez (Note 1) to fill a gap in clinical and experimental attributional measurement of affiliative behaviors. The original scale has two parts; the self and the other as actor perspectives. For the purposes of this study only the self portion was utilized. The gender specific equivalent of the other perspective was measured through an alternative method (See Procedure Section). The self portion of the EBR-ASQ taps two outcome orientations, success and failure, and three of the most important attributional dimensions, locus of causality, stability, and controllability, as delineated in the section on attributional style in the text. These dimensions were the dependent variables as outlined in the design section. Each dimension is a bipolar continuum anchored at each extreme by the appropriate antonyms. Five standardized sentence stems form the structure of the presentation of the 54 items. Each item consists of a stem 
followed by a causal attribution which taps into one or more of the attributional dimensions. Each item is rated on an 11 point Likert-type scale with zero being not at all descriptive, 5 being somewhat descriptive, and 10 being very descriptive (See Appendix A for the scale and item presentation). Each bipolar dimension is measured in all four perspective by outcome orientation cells. This combination yields 12 scores per subject. The dimensional scores are obtained by tallying the two unipolar or antonym item scores for each dimension, finding the difference between these two sub-scale scores, and adding a constant of ten to eliminate any negative values. For example, the locus of causality for self success dimensional score is obtained by tallying all the scores from the items which measure internality for self success, tallying all the scores from the items which measure externality for self success, finding the difference between these two subscale scores, and then adding ten.

Each dimensional score within each of the four perspective by outcome orientation cells has a possible range from zero to 20. A dimensional score above ten in any cell is indicative of perceptions of greater causal internality, stability, or controllability and a score below ten, of perceptions of greater causal externality, instability, or uncontrollability depending upon the dimension in question. The final set of 12 scores represents 
an individual's pattern of attributional preference or attributional style as measured on all three dimensions within all four perspective by outcome orientation cells. Table 2 details the procedure used for scoring each of the 12 scores.

\section{INSERT TABLE 2 ABOUT HERE}

The EBR-ASQ, then, is a short, easily administered scale which yields dimensional scores ideal for the empirical assessment required in this study. Overall, this scale has shown good reliability and validity coefficients as shown in Table 3. This scale is an adequate technique for the assessment required in this design.

\section{INSERT TABLE 3 ABOUT HERE}

\section{Procedure}

The overall procedure in this study was the administration and analysis of questionnaire data. Each of the 55 male and 52 female participants were requested to complete the self portion of the ERB-ASQ twice, once for themselves and once as if they were a member of the opposite sex. In order to control for any order effects half of the males and half of the females were given the opposite sex instruction set first. The participants were introduced to the experimenter and the study with the following verbal instructions: 


\begin{abstract}
"The purpose of this study is to gather data on different aspects of how people relate to one another. There are two identical questionnaires in each packet, but for each questionnaire the instructions are different. Please read and follow all of the instructions carefully. Although you will sign your name to both questionnaires in the packet these cover sheets will be removed so that no one will know how you answered. Answer quickly and honestly using your first impressions. You should be able to finish within 15 minutes. Are there any questions? Go ahead and start."
\end{abstract}

The questionnaires were then handed out and answered by the participants. The subject consent form was placed in front of the first questionnaire only and served as the cover sheet of the packet (See Appendix A for the Subject Consent Form). Following the subject consent form was the first page of the general instructions for answering the questionnaire.

This sheet also was presented only once at the beginning of the packet regardless of which condition was presented first. The instruction sheet read as follows:

INSTRUCTIONS

This is a questionnaire about what you believe are the causes of the ways you relate to people. In general, causes of events can differ in three ways. Causes can be:

1. inside or outside you;

2. stable or unstable over time; and

3. controllable by you or uncontrollable.

For example, trying hard or being smart are causes within you; whereas how hard a task is or luck are outside you. Certain aspects of your personality and the changing seasons are causes which are stable over time. On the other hand, fate and luck change over time. Finally, how hard you try is a cause that you can control; whereas the behavior of others is beyond your control. In completing this questionnaire it will be helpful if you keep these distinctions in mind.

In each of the following pages there is a statement about the way in which you relate to people followed by a list of possible causes. 
Read the statement and try to vividly imagine yourself in that situation. Then, after reading the instructions for that page, rate each of the causes on the basis of how descriptive of you that item is.

Answer all of the items and work as quickly as you can. Once you have answered all of the items in a page DO NOT go back over them and DO NOT change your answers.

GO ON TO THE NEXT PAGE.

This set of instructions was followed by one of the two following sets of instructions depending upon the perspective, self or opposite sex, that was presented first. Each subject received both sets of instructions at some point in the study. The instructions for the same sex or self perspective read as follows :

INSTRUCTIONS

Please fill in the blanks and circle the appropriate answers.

My name is

I am a

Male/Female

GO ON TO THE NEXT PAGE.

The instructions for the opposite sex perspective read as follows:

INSTRUCTIONS

As you know, there are differences between males and females. One of the purposes of this study is to gather data on how YOU perceive the differences between males and females. When answering this section of the questionnaire try to vividly imagine that you are a TYPICAL member of the opposite sex and how a TYPI $\overline{C A L}$ member of the opposite sex would feel in the following situations. My name is

Please Print

Please circle the appropriate answer. I am a MALE/FEMALE.

In the space provided below circle the sex opposite your own and then write it in the blank. 
For the purposes of this study I will answer as if I am a

\section{MALE/FEMALE}

REMEMBER, you are now answering as if you were a TYPICAL member of the opposite sex. GO ON TO THE NEXT PAGE.

(See Appendix A for all three actual instruction sheets).

\section{RESULTS}

Before performing the multi-variate analyses internal consistency analyses were performed on each dimensional subscale to determine if the EBR-ASQ maintained the previous acceptable levels of reliability with this test population. The results of these analyses as detailed in Table 4 indicated that overall the EBR-ASQ maintained a reasonable level of internal consistency and reliability with this test population.

\section{INSERT TABLE 4 ABOUT HERE}

As expected the preliminary analyses revealed no significant effects for the order of presentation of the self and opposite sex perspectives in the administration of the scale. These results appear in Table 5.

\section{INSERT TABLE 5 ABOUT HERE}

All further analyses, therefore, were conducted without an order of presentation covariate. 
Multivariate Tests

A 2 (Sex) x 2 (Perspective) x 2 (Outcome), repeated measures, multivariate analysis of variance was performed using the dimensional scores (locus of causality, stability, and controllability) as dependent variables. Multivariate tests of significance, using Hotelling's T square criterion, indicated significant main effects due to Sex, $\underline{F}(3,103)=4.30$, $\underline{\underline{p}}<.006 ;$ Perspective, $\underline{F}(3,103)=14.57, \underline{\underline{p}}<.001 ;$ and Outcome, $\underline{F}(3,103)=109.17, \underline{p}<.001$.

Univariate Tests

An examination of the univariate $F$ tests for the main effects of the three factors for each dependent variable revealed that of the nine analyses, eight were significant, although as revealed through an examination of the means, not always in the hypothesized direction. The method of scoring for the EBR-ASQ yields dimensional scores ranging from zero to twenty with scores above ten indicating perceptions of greater causal internality, stability, or controllability and scores below ten indicating the appropriate antonym for each bipolar scale. An examination of the means reveals the direction of the main effect (See Table 6) and

\section{INSERT TABLE 6 ABOUT HERE}

interaction results (See Tables 7 and 8 ). 
Main Effects

The main effects of sex was highly significant on the locus of causality dimension $\underline{F}(1,105)=9.11, \underline{p}<.01$. However, contrary to expectations females chose more internal attributions than did males. The main effect of sex was not significant on the stability dimension $\underline{F}(1,105)=1.96$, $\mathrm{p}<.164$. The main effect of Sex was significant on the controllability dimension $\underline{F}(1,105)=7.08, \underline{p}<.01$ and did support the hypothesis that overall males perceive greater causal controllability than do females. This result is somewhat misleading, however, and will be clarified in the discussion of the interaction results.

The main effect of Perspective was significant on the locus of causality dimension $\underline{F}(1,105)=30.33, \underline{p}<.001$ and the stability dimension $\underline{F}(1,105)=12.80, \underline{p}<.001$ and supported the hypotheses that individuals perceive greater causal internality and stability for the self than for members of the opposite sex. The main effect of Perspective was also significant on the controllability dimension $F(1,105)=3.94$, $\underline{p}<.05$, but contrary to expectations greater causal controllability was perceived in the opposite sex rather than in the self perspective. This unexpected turn of results will also be clarified in the discussion of the interaction results.

The main effect of Outcome for all three dimensions was highly significant and supported the hypotheses that individuals perceive greater causal internality, stability, and controllability for success than for failure $\underline{F}(1,105)=$ 
$214.8, \underline{\underline{p}}<.001, \underline{F}(1,105)=102.89, \underline{p}<.001$, and $\underline{F}(1,105)=10.26$, $\underline{p}<.001$, respectively.

Two-way interactions

Overall, the two-way interactions were not significant or supportive of the hypotheses. Furthermore, examination of the means revealed patterns of attributional preference which were often contrary to expectations (See Table 7).

\section{INSERT TABLE 7 ABOUT HERE}

The Sex by Perspective interaction was not significant on the locus of causality dimension $\underline{F}(1,105)=1.69, \underline{p}<.1963$. Both males and females chose somewhat more internal attributions for themselves than for members of the opposite sex. Contrary to expectations females perceived greater causal internality in both perspectives than did males. This result is consistent with the result for the main effect of sex on this dimension. In fact, females chose more internal attributions for males than the males chose for themselves.

The sex by Perspective interaction on the stability dimension approached significance $\underline{F}(1,105)=2.84, \underline{p}<.09$. males exhibited the expected pattern of choosing more stable attributions than did females in the self perspective while choosing more unstable attributions in the opposite sex perspective. Females also exhibited the expected pattern by choosing more stable attributions in the opposite sex perspective. 
The Sex by Perspective interaction was highly significant on the controllability dimension $\underline{F}(1,105)=23.18, \underline{p}<.001$, but the means revealed an unexpected pattern of attributional preference. In the self perspective females chose significantly more controllable attributions than did males. However, this pattern was reversed in the opposite sex perspective. In fact, males chose more controllable attributions in the opposite sex perspective than females chose for themselves. The perceptions of greater causal controllability in the opposite sex perspective by the males was so great as to influence both the main effects of sex and Perspective on this dimension which explains the significance and direction of those results.

The Sex by Outcome interaction yielded no significant results on any of the three dimensions with $\underline{F}(1,105)=.62$, $\underline{\mathrm{p}}<.4, \underline{F}(1,105)=.23, \underline{\mathrm{p}}<.6$, and $\underline{F}(1,105)=1.56, \underline{\mathrm{p}}<.2$ for the locus of causality, stability, and controllability dimensions respectively. The means again indicated that both males and females chose somewhat more internal attributions for success than for failure, consistent with the outcome main effect. However, females chose far more internal attributions for both success and failure than did males. The means from the stability and controllability dimensions revealed that both males and females chose somewhat more stable and controllable attributions for success than for failure in both perspectives, with males consistently perceiving somewhat greater causal stability and controllability. 
The Perspective by Outcome interaction was highly significant on all three dimensions with $\underline{F}(1,105)=6.61$, $\underline{p}<.01, \underline{F}(1,105)=8.22, \underline{p}<.01$, and $\underline{F}(1,105)=8.05, \underline{p}<.01$ for the locus of causality, stability, and controllability dimensions, respectively. In the self perspective individuals chose more internal, stable, and controllable attributions for success than for failure. This pattern was maintained in the opposite sex perspective on the locus of causality and controllability dimensions, but not to the same degree. However, on the stability dimension individuals chose more stable attributions for opposite sex failure than for success.

Three-Way Interactions

The sex by Perspective by Outcome interaction (see Table 8) was not significant on any of the three dimensions with $\underline{F}(1,105)=1.68, \underline{p}<.19$ for the stability dimension. However, as can be noted the locus of causality and controllability values approached significance with $\underline{F}(1,105)=2.58, \underline{\underline{p}}<.11$ and $\underline{F}(1,105)=2.93, \underline{p}<.08$ respectively. Although the three-way interaction was not significant on any of the three dimensions as expected an examination of the means is instructive because it reveals in greater detail the attributional preference of this test population. The pattern of attributional preference on the locus of causality dimension for the sex by Perspective by Outcome interaction maintained consistency with the main effects and the two-way interactions on this dimension. In both 
the self and opposite sex perspectives females perceived somwhat greater causal internality for both success and failure than did males. However, only in the failure outcome orientation did females perceive greater causal internality in the opposite sex perspective than the males perceived in the self perspective. Females, then, consistently perceive greater causal internality for themselves and for males for both success and failure. The previous pattern of attributional preference established in the main effect and two-way interaction results on the stability dimension was also maintained for the Sex by Perspective by Outcome interaction. This pattern, while not reaching statistical significance did show some support for the hypothesis that in the self perspective males view success as more stable than do females, although both males and females equally view failure as unstable. In the opposite sex perspective males perceive greater causal stability for success than do females. However, for failure this pattern is reversed. In fact, in the opposite sex perspective males perceive greater causal stability for failure than do females in the self perspective. Furthermore, females perceive opposite sex failure as highly unstable. This was the lowest mean score obtained on any of the dimensional measures $(\bar{X}=7.99)$.

The previous patterns established in the main effect and interaction results on the controllability dimension re-emerged in the Sex by Perspective by outcome interaction. 
In the self perspective both males and females perceived greater causal controllability for success than for failure. In the opposite sex perspective, however, males perceive greater causal controllability than do females for success. In fact, in the opposite sex perspective males view success as more controllable than either males or females view success in the self perspective. Furthermore, in the opposite sex perspective this strong pattern was maintained. In the opposite sex perspective again females perceive great causal uncontrollability for failure with this mean score being equal only to the opposite sex female perception of failure on the stability dimension $(\bar{X}-7.99)$.

The mean scores on both the stability and uncontrollability dimensions in the opposite sex perspective for failure, then, are consistent with the hypotheses that males perceive female failure as highly stable and controllable. The hypotheses were based on expectations of specific, multiple attributional patterns and the partial support of a portion of these hypotheses was not enough to reach and maintain statistical significance. There are many possible reasons for these enlightening but unexpected results. A few of these possibilities will be explored in the following discussion section. 


\section{DISCUSSION}

The results, although not totally supportive of the hypotheses, revealed differential, gender specific patterns of attributional preference for affiliative behavior. The purpose of this study was to determine if such patterns were extant, and to that end the expectations underlying the hypotheses were met. For example, the main effect of perspective was highly significant on all three dimensions; and although the means did not always fall in the expected direction, their significance indicated that individuals do indeed choose different causal attributions for themselves than they do for members of the opposite sex. The significance of this pattern was reaffirmed in the perspective by outcome interaction, where again individuals chose significantly different attributions for themselves than for members of the opposite sex for both success and failure. This general pattern of perceiving different causal agents as influential in self versus other involving outcomes follows that general pattern documented by Arkin and Duvall (1975), Deaux and Farris (1977), Miller (1976), and Nisbett, et al. (1973).

The hypothesized patterns of male and female attributional preference, however, were expected to mimic those patterns extant in achievement behaviors. The helplessness training given to females for achievement behaviors was expected to generalize over to affiliative behaviors, and the effects of this training were expected to be moderated only by the supposition that affiliation is the female sex-role appropriate 
analogue to male achievement behavior. The results indicated the weakness of the helplessness training generalization and the strength of affiliation as the female sex-role appropriate analogue to male achievement behavior. That is, overall, both males and females perceived the causes of female affiliative outcomes to be more internal, less stable, and more controllable than male affiliative outcomes. This pattern is suggestive of beliefs in greater competence and lability in female affiliative behavior, supportive of the analogue theory.

No where was this effect more evident that on the locus of causality dimension. The main effect of sex revealed that when summing across both perspectives and both outcomes females maintained perceptions of significantly greater causal internality than did males. The sex by perspective, sex by Outcome, and Sex by Perspective by Outcome interactions, although not significant, indicated that males and females followed essentially the same general patterns of causal ascription with females consistently perceiving greater causal internality. That is, both males and females had parallel patterns of attributional preference by perceiving greater causal internality for the self versus the opposite sex, and success versus failure. This parallel pattern is similar to that proposed to exist by Peterson, et al. (1980). Furthermore, the females' perceptions of greater internality in both perspectives and both outcomes is that first link in an attributional chain indicative of a belief in greater female competence in affiliative behaviors. 
Before discussing the results of the stability and controllability dimensions it should be noted that the mean scores on these two dimensions consistently fell below ten. With the data currently available on the scale it is not possible to ascertain whether this is an indication of an overall pattern of belief in causal instability and uncontrollability or merely an artifact of the way the scale was constructed. Either way it is a noteworthy point. The pattern of results obtained on the stability dimension appeared to indicate an overall belief in causal instability. The main effect of sex was not significant on this dimension due to the number and magnitude of the interactions. This was the only dimension upon which this main effect was not significant. The sex by Perspective interaction approached significance. That is, both males and females perceived greater causal instability for the females' outcomes and greater causal stability by comparison for the males' outcomes. The sex by Outcome interaction was not significant but an examination of the means indicated that both males and females perceived somewhat greater causal stability for self versus opposite sex outcomes, and success versus failure outcomes. The sex by Perspective by Outcome interaction was also not significant, but again the means indicated the maintenance of the previously established patterns on this dimension. These results, although somewhat supportive of the hypotheses, do not in themselves indicate a belief in less female competence in affiliative behavior. 
The pattern of attributional preference indicative of a belief in greater female competence is a combination of the three attributional dimensions, and of these three stability is that dimension which moderates the effects produced by the other two. The results from this dimension, then, indicate not a belief in a lesser competence, but instead a belief in a less stable competence; indicative of the perception of effort as opposed to ability as the influential causal agent.

The pattern of results obtained on the controllability dimension again appeared to indicate an overall belief in causal uncontrollability for affiliative behavior. However, again this may be simply an artifact of scale construction. The main effect of sex was highly significant and the means indicated that males perceived greater causal controllability than did females. This main effect, although apparently supportive of the hypothesis that males perceive greater causal controllability than do females, is misleading. The Sex by Perspective interaction was also highly significant and clarified the confusion of the main effect by revealing that both males and females perceived greater causal controllability for females than for males. The significant main effect of Sex, then, was due to the males' overwhelming perception of greater causal controllability in the opposite sex perspective. The magnitude of this score was so great as to influence the significance of the main effect of sex. The sex by Outcome interaction, however, was not significant 
but the means revealed a parallel pattern of attributional preference between males and females, whereby greater causal controllability was perceived for success versus failure with males appearing to perceive greater overall causal controllability. Again, this apparent perception was due to the males' perception of greater causal controllability in the opposite sex perspective. The sex by Perspective by Outcome interaction approached significance. The means from this interaction again indicated that both males and females perceived greater causal controllability for females. This pattern is the final link in the attributional chain indicative of a belief in greater female competence in affiliative behaviors.

The main effect of Outcome was significant on all three dimensions with the means indicating a belief in greater causal internality, stability, and controllability for success versus failure. These results support the general pattern of attributional preference documented by Arkin, et al (1980), Feather and Simon (1973), Kuiper (1978), Miller (1976), Sobel (1974), and Struefert and Struefert (1969).

So although the results were not totally supportive of all of the hypotheses, overall, they did lend some support to the theories that individuals choose different types of causal attributions for themselves than for members of the opposite sex, that individuals choose different causal attributions to explain success versus failure, and that to some extent males and females have similar patterns of attributional preference for affiliative behavior, differing 
mostly in magnitude. What is most surprising, and delightfully so, is that females do not show the expected learned helplessness pattern of attributional preference for affiliative behavior. What has emerged is an attributional pattern that is indicative of a belief in a greater female competence in affiliative behaviors.

Thus far the results have been discussed individually and not together within the framework of attributional style. The concept of style is most important in determining and understanding the affective consequences of attributional preferences. However, a thorough understanding of the individual findings is prerequisite to understanding the implications they present within the framework of attributional style.

The predominant attributional style for the male test population is more internal, stable, and uncontrollable (e.g., attributions to ability and/or mood) for self success; less internal, stable, and controllable (e.g., attributions to luck and/or chance) for self failure; more internal, unstable, and controllable (e.g., attributions to immediate effort) for opposite sex success; and less internal, stable, and uncontrollable (e.g., attributions to effects from other sources) for opposite sex failure. This male affiliative attributional style is one of universal helplessness and is conducive to giving up and not trying after failure. However, it is not one of affiliative depression. 
The predominant attributional style for the female test population is more internal, stable, and controllable (e.g., attributions to typical effort and motivation) for self success; more internal, unstable, and uncontrollable (e.g., attributions to moods and emotions) for self failure; more internal, unstable, and controllable (e.g., attributions to effects from other sources) for opposite sex failure. This affiliative attributional style is conducive to increased effort after failure, and is one of a belief in more personal competence.

These two general attributional styles indicate that affiliation, does indeed, appear to be the female sex-role appropriate analogue to male achievement behavior. Further, the mastery oriented attributional styles reinforced in males for achievement behaviors appear also to be reinforced in females for affiliative behaviors.

Several problems in this study must be noted before closing. The scale used to measure the attributional preference of the males and females in this study was a relatively new device designed for clinical and empirical assessment of this nature. Although the initial validity and reliability coefficients were acceptable and the reliability and internal consistency coefficients from this test population maintained the previous acceptable levels, this study was the first extra-developmental usage. As such, some requisite information was unavailable. In particular, it is unclear whether the low scores on the stability and controllability dimensions are indicative of beliefs in overall causal instability and 
uncontrollability or merely artifacts of the method of scale construction. However, these few problems not withstanding, the EBR-ASQ is a valid and reliable instrument and is still the technique of choice for this study.

Another factor which may have been influential in determining the outcomes is the mean age difference between the male and female populations. The male population was somewhat younger than the female population and this age difference, although not great, may have been a confounding influence. The third possible problem is the possible confounding influence of the sex of the experimenter. The experimenter administering all of the questionnaires was female. A replication of this study using both male and female experimenters would perhaps provide a different pattern of results. The fourth possible problem is the type of test population; the majority of subjects for this study were drawn from a large, private university. The results of this study, then, may not be unequivocally generalized to other populations, but may provide an indication of what might be expected from other test populations.

In conclusion, the results, although not unequivocally applicable to all populations, indicate that affiliation is the female sex-role appropriate analogue to male achievement behavior; and as achievement competence and success are male sex-role appropriate, affiliation competence and success are female sex-role appropriate. The pattern of causal attributional preference for female achievement success and 
failure is that pattern which appears here for male affiliative success and failure. This study fills a gap in the research on gender specific cognitive styles; a gap which will be filled soon with other studies indicating a decline in the reliance on sex-role stereotypes and behavioral limitations. 
TABLE 1

TABULAR PRESENTATION OF THE 2 (SEX) $\times 2$ (PERSPECTIVE) $\times 2$ (OUTCOME)

FACTORIAL DESIGN

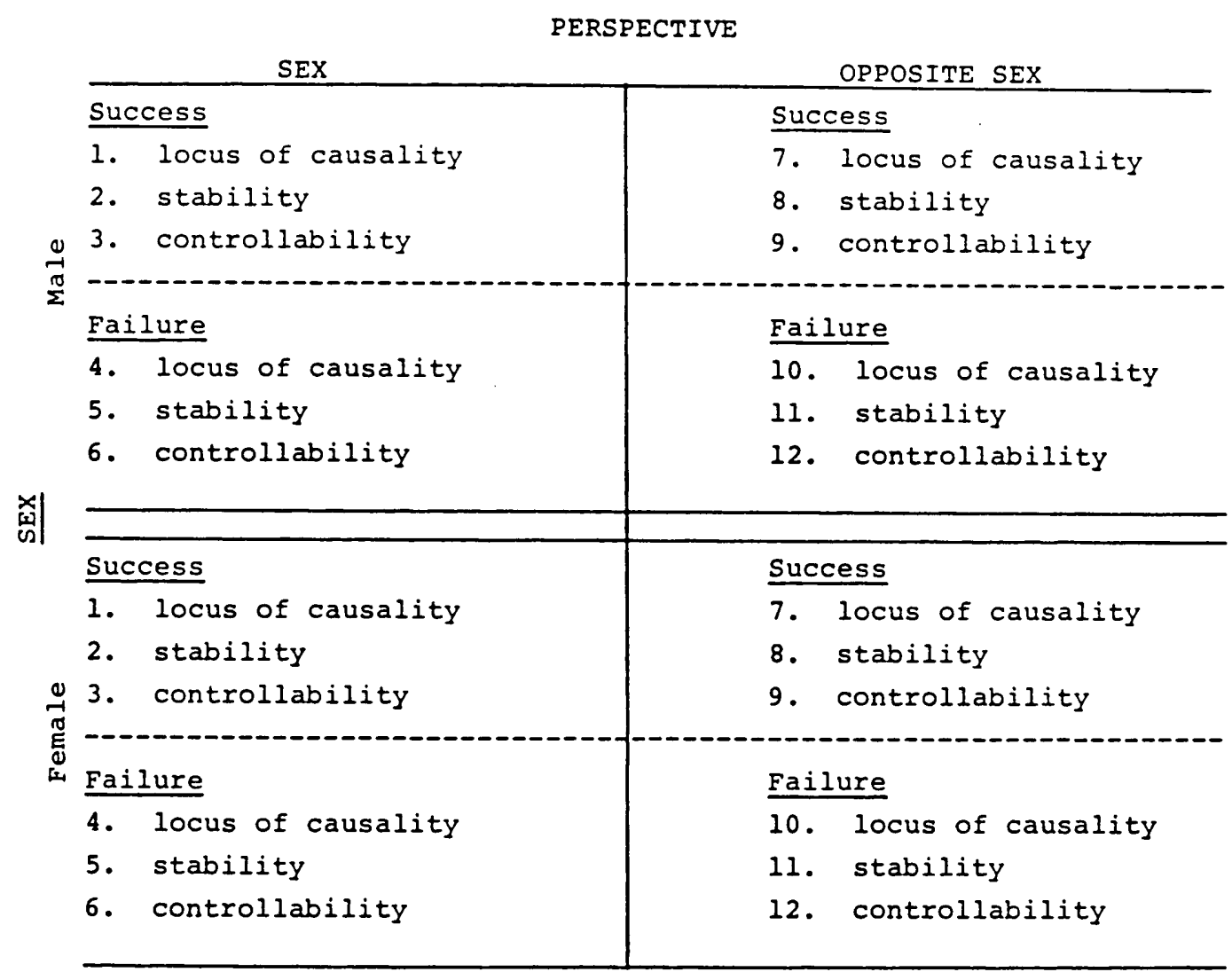


TABLE 2

\section{DEPENDENT VARIABLES}

Scoring technique for the three dimensions that are the dependent variables for each subject.

SELF Success

Locus of Causality

Stability

Controllability

SELF Failure

Locus of Causality

Stability

Controllability
This dimensional score $=$ the difference between internality for self success and externality for self success plus ten to eliminate negative numbers.

This dimensional score $=$ the difference between stability for self success and instability for self success plus ten to eliminate negative numbers.

This dimensional score $=$ the difference between controllability for self success and uncontrollability for self success plus ten to eliminate negative numbers.

This dimensional score $=$ the difference between internality for self failure and externality for self failure plus ten to eliminate negative numbers.

This dimensional score $=$ the difference between stability for self failure and instability for self failure plus ten to eliminate negative numbers.

This dimensional score = the difference between controllability for self failure and uncontrollability for self failure plus ten to eliminate negative numbers. 
TABLE 2

(cont'd.)

DEPENDENT VARIABIES

Scoring technique for the three dimensions that

are the dependent variables for each subject

\section{OPPOSITE SEX SuccesS}

Locus of Causality

Stability

Controllability

OPPOSITE SEX Failure

Locus of Causality

Stability

Controllability
This dimensional score = the difference between internality for opposite sex success and externality for opposite sex success plus ten to eliminate negative numbers.

This dimensional score = the difference between stability for opposite sex sucess and instability for opposite sex success plus ten to eliminate negative numbers.

This dimensional score = the difference between controllability for opposite sex success and uncontrollability for opposite sex success plus ten to eliminate negative numbers.

This dimensional score = the difference between internality for opposite sex failure and externality for opposite sex failure plus ten to eliminate negative numbers.

This dimensional score = the difference between stability for opposite sex failure and instability for opposite sex failure plus ten to eliminate negative numbers.

This dimensional score = the difference between controllability for opposite sex failure and uncontrollability for opposite sex failure plus ten to eliminate negative numbers. 
TABLE 3

MEANS, STANDARD DEVIATIONS, INTERNAL CONSISTENCY COEFFICIENTS, AND FIVE-WEEK TEST-RETEST RELIABILITY COEFFICIENTS FOR THE EBR-ASQ ATTRIBUTIONAL DIMENSIONS

\begin{tabular}{|c|c|c|c|c|}
\hline SUCCESS & $\begin{array}{r}\text { SELF } \\
\text { MEAN }\end{array}$ & $\begin{array}{r}\text { PERSPECTIVE } \\
\text { STD. DEV. }\end{array}$ & $\begin{array}{c}\text { CRONBACH'S } \\
\text { ALPHA }\end{array}$ & $\begin{array}{r}\text { TEST- } \\
\text { RETEST } \\
\end{array}$ \\
\hline Locus of Causality & 15.1 & 2.1 & .63 & .68 \\
\hline Stability & 10.4 & 2.3 & .62 & .62 \\
\hline Controllability & 8.3 & 2.1 & .62 & .30 \\
\hline \multicolumn{5}{|l|}{ FAILURE } \\
\hline Locus of Causality & 11.9 & 2.0 & .77 & .58 \\
\hline Stability & 9.0 & 2.9 & .70 & .45 \\
\hline Controllability & 8.2 & 1.9 & .56 & .47 \\
\hline
\end{tabular}

From: Escovar, Brown, and Rodriguez (Note 1). 
TABLE 4

MEANS, STANDARD DEVIATIONS, INTERNAL

CONSISTENCY AND STANDARDIZED ITEM COEFFICIENTS

FOR THE EBR-ASQ ATTRIBUTIONAL DIMENSIONS - TEST POPULATION

\begin{tabular}{|c|c|c|c|c|}
\hline \multicolumn{5}{|c|}{ SELF PERSPECTIVE } \\
\hline SUCCESS & MEAN & STD. DEV. & $\begin{array}{c}\text { CRONBACH'S } \\
\text { ALPHA }\end{array}$ & $\begin{array}{l}\text { STD. ITEM } \\
\text { ALPHA }\end{array}$ \\
\hline Locus of Causality & 14.32 & 1.94 & .54 & .77 \\
\hline Stability & 10.24 & 1.50 & .79 & .82 \\
\hline Controllability & 8.63 & 1.56 & .28 & .67 \\
\hline \multicolumn{5}{|l|}{ FAILURE } \\
\hline Locus of Causality & 11.79 & 1.49 & .78 & .88 \\
\hline Stability & 8.49 & 1.33 & .69 & .85 \\
\hline \multirow[t]{2}{*}{ Controllability } & 8.34 & 1.37 & .87 & .88 \\
\hline & OPPOSITE & SEX PERSPECT & VE & \\
\hline SUCCESS & MEAN & STD. DEV. & $\begin{array}{c}\text { CRONBACH 'S } \\
\text { ALPHA }\end{array}$ & $\begin{array}{c}\text { STD. ITEM } \\
\text { ALPHA }\end{array}$ \\
\hline Locus of Causality & 13.40 & 1.79 & .65 & .84 \\
\hline Stability & 9.52 & 1.65 & .77 & .82 \\
\hline Controllability & 9.08 & 1.48 & .56 & .77 \\
\hline \multicolumn{5}{|l|}{ FAILURE } \\
\hline Locus of Causality & 11.38 & 1.56 & .78 & .86 \\
\hline Stability & 8.35 & 1.53 & .87 & .87 \\
\hline Controllability & 8.26 & 1.48 & .73 & .82 \\
\hline
\end{tabular}


TABIE 5

SIGNIFICANCE OF ORDER EFFECTS

DIMENSIONS

SUCCESS

Locus of Causality

Stability

Controllability

\section{FAILURE}

Locus of Causality

Stability

Controllability
$\underline{D F}$

2,104

2,104

2,104

2, 104

2,104

2,104 $\underline{\text { F VALUE }}$

2.19

.02

1.42

$\underline{\mathrm{P} \text { VAIUE }}$

.117

.977

.245

.751

.888

.527 


\section{TABLE 6}

SEX, PERSPECTIVE, AND OUTCOME MEANS BY DIMENSIONS AS COMPARED IN THE MAIN EFFECTS ANALYSES

\begin{tabular}{|c|c|c|c|}
\hline MAIN EFFECT & DIMENSION & LEVEL & MEAN \\
\hline \multirow{6}{*}{ Sex } & \multirow{2}{*}{ Locus of Causality } & Male & 12.38 \\
\hline & & Female & 13.09 \\
\hline & \multirow{2}{*}{ Stability } & Male & 9.28 \\
\hline & & Female & 9.01 \\
\hline & \multirow[t]{2}{*}{ Controllability } & Male & 8.80 \\
\hline & & Female & 8.34 \\
\hline \multirow{2}{*}{\multicolumn{2}{|c|}{ Locus of Causality }} & Self & 13.05 \\
\hline & & Opposite Sex & 12.39 \\
\hline \multirow[t]{4}{*}{ Perspective } & \multirow{2}{*}{ stability } & Self & 9.37 \\
\hline & & Opposite Sex & 8.93 \\
\hline & \multirow{2}{*}{ Controllability } & Self & 8.49 \\
\hline & & Opposite Sex & 8.67 \\
\hline \multirow{2}{*}{\multicolumn{2}{|c|}{ Locus of Causality }} & Success & 13.86 \\
\hline & & Failure & 11.59 \\
\hline \multirow[t]{4}{*}{ Outcome } & \multirow{2}{*}{ Stability } & Success & 9.88 \\
\hline & & Failure & 8.42 \\
\hline & \multirow[t]{2}{*}{ Controllability } & Success & 8.85 \\
\hline & & Failure & 8.30 \\
\hline
\end{tabular}


TABLE 7

SEX BY PERSPECTIVE, SEX BY OUTCOME, AND PERSPECTIVE BY OUTCOME MEANS BY DIMENSIONS AS COMPARED IN THE TWO-WAY INTERACTION ANALYSES.

\begin{tabular}{|c|c|c|c|c|}
\hline INTERACTION & DIMENSION & LEVEL I & LEVEL II & MEAN \\
\hline & \multirow[t]{2}{*}{ Locus of Causality } & Self & $\begin{array}{l}\text { Male } \\
\text { Female }\end{array}$ & $\begin{array}{l}12.63 \\
13.50\end{array}$ \\
\hline & & Opposite Sex & $\begin{array}{l}\text { Male } \\
\text { Female }\end{array}$ & $\begin{array}{l}12.12 \\
12.68\end{array}$ \\
\hline $\begin{array}{r}\text { Sex } \\
\text { By }\end{array}$ & \multirow[t]{2}{*}{ stability } & Self & $\begin{array}{l}\text { Male } \\
\text { Female }\end{array}$ & $\begin{array}{l}9.40 \\
9.33\end{array}$ \\
\hline Perspective & & Opposite Sex & $\begin{array}{l}\text { Male } \\
\text { Female }\end{array}$ & $\begin{array}{l}9.17 \\
9.47\end{array}$ \\
\hline \multirow{4}{*}{\multicolumn{2}{|c|}{ Locus of Causality }} & Self & $\begin{array}{l}\text { Male } \\
\text { Female }\end{array}$ & $\begin{array}{l}8.50 \\
8.69\end{array}$ \\
\hline & & Opposite Sex & $\begin{array}{l}\text { Male } \\
\text { Female }\end{array}$ & $\begin{array}{l}9.11 \\
8.20\end{array}$ \\
\hline & & Success & $\begin{array}{l}\text { Male } \\
\text { Female }\end{array}$ & $\begin{array}{l}13.45 \\
14.29\end{array}$ \\
\hline & & Failure & $\begin{array}{l}\text { Male } \\
\text { Female }\end{array}$ & $\begin{array}{l}11.30 \\
11.89\end{array}$ \\
\hline $\begin{array}{r}\text { Sex } \\
\text { By }\end{array}$ & \multirow[t]{2}{*}{ stability } & Success & $\begin{array}{l}\text { Male } \\
\text { Female }\end{array}$ & $\begin{array}{l}9.98 \\
9.77\end{array}$ \\
\hline Outcome & & Failure & $\begin{array}{l}\text { Male } \\
\text { Female }\end{array}$ & $\begin{array}{l}8.59 \\
8.24\end{array}$ \\
\hline \multirow{4}{*}{\multicolumn{2}{|c|}{ Locus of Causality }} & Success & $\begin{array}{l}\text { Male } \\
\text { Female }\end{array}$ & $\begin{array}{l}9.18 \\
8.51\end{array}$ \\
\hline & & Failure & $\begin{array}{l}\text { Male } \\
\text { Female }\end{array}$ & $\begin{array}{l}8.42 \\
8.17\end{array}$ \\
\hline & & Success & $\begin{array}{l}\text { Self } \\
\text { Opposite Sex }\end{array}$ & $\begin{array}{l}14.32 \\
13.40\end{array}$ \\
\hline & & Failure & $\begin{array}{l}\text { Self } \\
\text { Opposite Sex }\end{array}$ & $\begin{array}{r}11.79 \\
9.52\end{array}$ \\
\hline $\begin{array}{c}\text { Perspective } \\
\text { By }\end{array}$ & \multirow[t]{2}{*}{ stability } & Success & $\begin{array}{l}\text { Self } \\
\text { Opposite Sex }\end{array}$ & $\begin{array}{r}10.24 \\
9.08\end{array}$ \\
\hline Outcome & & Failure & $\begin{array}{l}\text { Self } \\
\text { Opposite Sex }\end{array}$ & $\begin{array}{r}8.49 \\
11.38\end{array}$ \\
\hline & \multirow[t]{2}{*}{ Controllability } & Success & $\begin{array}{l}\text { Self } \\
\text { Opposite Sex }\end{array}$ & $\begin{array}{l}8.63 \\
8.35\end{array}$ \\
\hline & & Failure & $\begin{array}{l}\text { Self } \\
\text { Opposite Sex }\end{array}$ & $\begin{array}{l}8.34 \\
8.26\end{array}$ \\
\hline
\end{tabular}




\section{TABLE 8}

SEX BY PERSPECTIVE BY OUTCOME MEANS BY DIMENSIONS AS COMPARED IN THE THREE-WAY INTERACTION ANALYSES.

\begin{tabular}{|c|c|c|c|c|}
\hline DIMENSION & LEVEL I & LEVEL II & LEVEL III & MEAN \\
\hline \multirow{8}{*}{ Locus of Causality } & \multirow{4}{*}{ Self } & \multirow[t]{2}{*}{ Success } & Male & 13.76 \\
\hline & & & Female & 14.91 \\
\hline & & \multirow{2}{*}{ Failure } & Male & 11.50 \\
\hline & & & Female & 12.09 \\
\hline & \multirow{4}{*}{ Opposite Sex } & \multirow{2}{*}{ Success } & Male & 13.15 \\
\hline & & & Female & 13.67 \\
\hline & & \multirow{2}{*}{ Failure } & Male & 11.09 \\
\hline & & & Female & 11.69 \\
\hline \multirow{8}{*}{ Stability } & \multirow{4}{*}{ Self } & \multirow[t]{2}{*}{ Success } & Male & 10.31 \\
\hline & & & Female & 10.17 \\
\hline & & \multirow[t]{2}{*}{ Failure } & Male & 8.49 \\
\hline & & & Female & 8.49 \\
\hline & \multirow{4}{*}{ Opposite Sex } & \multirow[t]{2}{*}{ Success } & Male & 9.65 \\
\hline & & & Female & 9.37 \\
\hline & & \multirow[t]{2}{*}{ Failure } & Male & 8.68 \\
\hline & & & Female & 7.99 \\
\hline \multirow{8}{*}{ Controllability } & \multirow{4}{*}{ Self } & \multirow[t]{2}{*}{ Success } & Male & 8.67 \\
\hline & & & Female & 8.60 \\
\hline & & \multirow[t]{2}{*}{ Failure } & Male & 8.33 \\
\hline & & & Female & 8.36 \\
\hline & \multirow{4}{*}{ Opposite Sex } & \multirow[t]{2}{*}{ Success } & Male & 9.70 \\
\hline & & & Female & 8.42 \\
\hline & & \multirow[t]{2}{*}{ Failure } & Male & 8.51 \\
\hline & & & Female & 7.99 \\
\hline
\end{tabular}




\section{Appendix A}


EBR ATTRIBUTIONAL STYLE QUESTIONNAIRE

Copyright (C) 1982 by Luis A. Escovar, Ph.D.; Gretchen A. Brown, B.A.: and Rolando D. Rodriguez, B.A.

All rights reserved. 
SUBJECT CONSENT FこPM

I give my informed consent to partiaipate in this study the purpose of which is to gather cata on different aspects of the way in which people relate to each other. I consent to publication of the results of this study so long as the information is anonymous and disguised so that no identification can be made. I understand that my participation in this study will involve my answering a questionnaire about the way I relate to other people. Furthermore, I understand that there are no known expected risks or discomforts, and that there is no deception of any kind in this study. Finally, I understand that I an free to refuse answering the questionnaire and to withdraw from the study at any time, for any reason, without penalty of any kind.

signature of participant in study

date

Researcher: Dr. Luis A. Escovar

DM 435-B.

Florida International University

554-2880 


\section{INSTRECTIONS}

rifis is a questionnaire about what you belfeve are the causes for the ways you relate to people. In general, causes of events ean differ in three ways. Causes can be:

1. Instde or outside you:

2. stable or unstable over time: and

3. controllable by you or uncontrollable.

For example, trying hard or being smart are causes which are within you: whereas how hazd a task is or luek are outside you. Certain aspects of your personality and the changing of the seasons are causes which are stable over ti=e. On the other hand, fate and luck can change over time. Flnally, how hard you try is a cause that you can control; whereas the behavioz of others is beyond your contzol. In completing this questionnaize it will be belpful if you keep these distinctlons in mind.

In each one of the following pages there is a statement about the way in whlch you relate to people followed by a list of possible causes. Read the statement and try to vividly imagine yourself is that situation. Then, after reading the instructions for that page, rate each of the causes on the basis of how descriptive of you that item is.

Answer all ltems and work as gulekly as you can. Once you have answered all of the ftems in a page Do nOr go back over them and Do NOT change your answers 


\section{INSTRIICTINNS}

Please fill in the blanks and Circle the appropriate ANSWERS,

Hy name is

I AM A

$$
\text { MaLe/Female, }
$$




\section{INSTRUCTIONS}

AS YOU KNOW, THERE ARE DIFFFRENCES BETWEEN MALES AND FEMALES, nNE OF THE PURPOSES OF THIS STUDY IS TO GATHER DATA ON HOW YOUI PERCEIVE THE DIFFERENCES BETWEEN MALES AND FEMALES, WHEN ANSWERING THIS SECTION OF THE QUESTIONNAIRE TRY TO VIVIDLY IMAGINE THAT YOU ARE A TYPICAL MEMBER OF THE OPPOSITE SEX AND HOW A TYPICAL MEMBER OF THE. OPPOSITE SEX WOULD FEFL IN THE FOLLOWING SITUATIONS,

MY NAME IS

$$
\text { Please Print }
$$

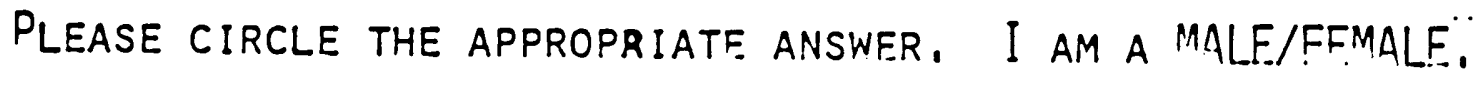

IN THE SPACE PROVIDED BELOW CIRCLE THE SEX OPPOSITE YOUR ONN AND THEN WRITE IT IN THE BLANK.

FOR THE PURPOSES OF THIS STUDY I WILL ANSWFR AS IF I AM A MALE/FEMALE

REMEMBER, YOU ARE NOW ANSWERING AS IF YOU WERE A TYPICAL MEMBER OF THE OPPOSITE SEX. 
1.

STATEMENT: I find it easy to make friends.

INSTRUCIIONS: Try to vividly imazine that the above statement applies to you. Now proceed to zate each one of the causes which appear below the broken line on the basis of how well that item describes you, with $0=$ not descriptive at all, and $10=v e r y$ descriptive of me. You can mark any numer between 0 and 10 depending on how well that item describes you.

not descriptive

of me at all somewhat

descriptive

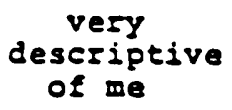

$\begin{array}{lllllllllll}0 & 1 & 2 & 3 & 4 & 5 & 6 & 7 & 8 & 9 & 10\end{array}$

1. I find it easy to make friends when I an not tired.
01
2
45
67
8910

2. I find it easy to make friends because $I$ always try to be friendly.
012
$\begin{array}{llll}7 & 8 & 9 & 10\end{array}$

3. I find it easy to make friends wherever I try to make myself attractive.

$\begin{array}{lllllllllll}0 & 1 & 2 & 3 & 4 & 5 & 6 & 7 & 8 & 9 & 10\end{array}$

4. I find it easy to make friends because I usually seem to be at the right place at the right time.
0
1
23
3
45
$\begin{array}{llll}6 & 7 & 8 & 9\end{array}$
10

5. I find it easy to make friends when I an feeling good.

$\begin{array}{lllllllllll}0 & 1 & 2 & 3 & 4 & 5 & 6 & 7 & 8 & 9 & 10\end{array}$

6. I find it easy to make friends because I am good natured.
01
23
4
67
89
10

7. I find it easy to make friends because making friends is simple.

$\begin{array}{lllllllllll}0 & 1 & 2 & 3 & 4 & 5 & 6 & 7 & 8 & 9 & 10\end{array}$

8. I find It easy to make friends whenever I am with as attractive person.

$\begin{array}{lllllllllll}0 & 1 & 2 & 3 & 4 & 5 & 6 & 7 & 8 & 9 & 10\end{array}$ 
STATEMENT: I am not popular.

INSTRUCTIONS: Try to vividly imagine that the above statement applies to you. Now proceed to rate each one of the causes which appear below the broken line on the basis of how well that item describes you, with $0=$ not descriptive at all, and 10 nery descriptive of me. you can mark any number between 0 and 10 depending on how well that item describes you.

not descriptive of me at all somewhat

descriptive

\section{very \\ descriptive \\ of me}

$\begin{array}{lllllllllll}0 & 1 & 2 & 3 & 4 & 5 & 6 & 7 & 8 & 9^{\circ} & 10\end{array}$

9. I an not very popular because my prayers are not always answered.

$\begin{array}{lllllllllll}0 & 1 & 2 & 3 & 4 & 5 & 6 & 7 & 8 & 9 & 10\end{array}$

10. I an not very popular whenever my clothes are not stylish.

1

2

3

4

5

6

7

8910 
STATEMENT: I an well liked.
INSTRUCTIONS: Try to vividly imagine that the above statenent applies to you. Now proceed to rate each one of the causes which appear below the broken line on the basis of how well that itern de- scribes you, with $0=$ not descriptive at all. and $10=v e r y$ descriptive of me. You can mark any number between 0 and 10 depending on how well that item describes you.

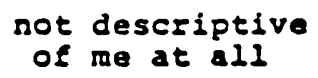

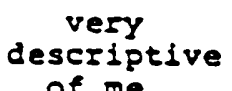

of me

$\begin{array}{lllllllllll}0 & 1 & 2 & 3 & 4 & 5 & 6 & 7 & 8 & 9^{\circ} & 10\end{array}$

11. I am well liked because I always try to relate to people. $\begin{array}{lllllllllll}0 & 1 & 2 & 3 & 4 & 5 & 6 & 7 & 8 & 9 & 10\end{array}$

12. I am well liked because getting people to like you reguires very little work.
12
45
$\begin{array}{llllll}5 & 6 & 7 & 8 & 9 & 10\end{array}$

13. I an well like because I usually get good breaks.
0 I
1.2
23
3
56
7
89
10

14. I am well liked whenever I have money.
01
12
23
3
45
67
8910

When you finish working on this page go on to the next one. Do not return to this page. 
STATEMENT: I do not get along well with people.

INSTRUCTIONS: Try to vividly imagine that the above statement applies to you. Now proceed to rate each one of the causes which appear below the broken line on the basis of how well that item describes you, with $0=$ not descriptive at all, and 10 -very descriptive of me. You can mark any number between 0 and 10 depending on how well that item describes you.

not descriptive

of we at all

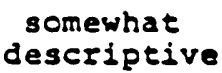

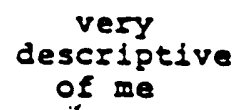
of me

$$
\begin{array}{lllllllllll}
0 & 1 & 2 & 3 & 4 & 5 & 6 & 7 & 8 & 9 & 10
\end{array}
$$

15. I do not get along well with people because I do not have a very good sense of humor.

$$
\begin{array}{lllllllllll}
0 & 1 & 2 & 3 & 4 & 5 & 6 & 7 & 8 & 9 & 10
\end{array}
$$

16. I don't get along well with people whenever I don't put much effort into it.

$\begin{array}{lllllllllll}0 & 1 & 2 & 3 & 4 & 5 & 6 & 7 & 8 & 9 & 10\end{array}$

17. I do not get along well with people because I have failed to get God to love me.
$\begin{array}{lllllllllll}0 & 1 & 2 & 3 & 4 & 5 & 6 & 7 & 8 & 9 & 10\end{array}$

18. I do not get along well with people whenever I don't look good.

$\begin{array}{lllllllllll}0 & 1 & 2 & 3 & 4 & 5 & 6 & 7 & 8 & 9 & 10\end{array}$

19. I don't get along well with people when I am depressed. $\begin{array}{lllllllllll}0 & 1 & 2 & 3 & 4 & 5 & 6 & 7 & 8 & 9 & 10\end{array}$

20. I don't get along well with people because that's the way the cards usually fall.

$\begin{array}{lllllllllll}0 & 1 & 2 & 3 & 4 & 5 & 6 & 7 & 8 & 9 & 10\end{array}$

21. I do not get along well with people because I usually don't pay much attention to them.

$\begin{array}{lllllllllll}0 & 1 & 2 & 3 & 4 & 5 & 6 & 7 & 8 & 9 & 10\end{array}$


STATEMENT: I find it easy to talk to people.

INSTRUCTIONS: TFY to vividly Imagine that the above statement applies to you. Now proceed to zate each one of the causes which appear below the broken line on the basis of how well that item describes you, with $0=$ not descriptive at all, and $10=v e r y$ descriptive of me. You can mark any number between 0 and 10 depending on how well that 1 tem describes you.

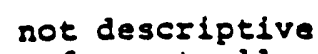

\section{somewhat \\ descriptive}

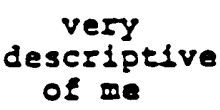

\section{$\begin{array}{lllllllllll}0 & 1 & 2 & 3 & 4 & 5 & 6 & 7 & 8 & 9 & 10\end{array}$}

22. I find it easy to talk to people when I an in the mood. $\begin{array}{lllllllllll}0 & 1 & 2 & 3 & 4 & 5 & 6 & 7 & 8 & 9 & 10\end{array}$

23. I find it easy to talk to people when things are going my way.
01
2
4
5
7
8910

24. I find it easy to talk to people because I always try to be an understanding person.
01
2
5
$\begin{array}{lllll}6 & 7 & 8 & 9 & 10\end{array}$

25. I find it easy to talk to people because I am intelligent.
$\begin{array}{lllllllllll}0 & 1 & 2 & 3 & 4 & 5 & 6 & 7 & 8 & 9 & 10\end{array}$

26. I find it easy to talk to people whenever I make an effort to be outgoing.
0
12
3
5
$\begin{array}{llll}7 & 8 & 9 & 10\end{array}$

27. I find it easy to talk to people because my religious practices give me the power to succeed.
0
1
23
4
5
$6 \quad 7 \quad 8$
10 
STATENENT: I an not well liked.

INSTRUCTIONS: Try to vividly imagine that the above statement applies to you. Now proceed to rate each one of the causes which appear below the broken line on the basis of how well that iten describes you, with $0=$ not descriptive at all, and 10=very descriptive of me. You can mark any number between 0 and 10 depending on how well that item describes you.

not descriptive

of me at all

somewhat

descriptive

very
descriptive

$\begin{array}{lllllllllll}0 & 1 & 2 & 3 & 4 & 5 & 6 & 7 & 8 & 9 & 10\end{array}$

28. I am not well liked because I usually get bad breaks.

$\begin{array}{lllllllllll}0 & 1 & 2 & 3 & 4 & 5 & 6 & 7 & 8 & 9 & 10\end{array}$

29. I an not well liked because there is a powerful being that has not interceded for me whenever I have asked it to do so.

$\begin{array}{lllllllllll}0 & 1 & 2 & 3 & 4 & 5 & 6 & 7 & 8 & 9 & 10\end{array}$

30. I am not well liked because getting people to like you requires a lot of work.

$\begin{array}{lllllllllll}0 & 1 & 2 & 3 & 4 & 5 & 6 & 7 & 8 & 9 & 10\end{array}$

31. I am not well liked because I never try to relate to people.

$\begin{array}{lllllllllll}0 & 1 & 2 & 3 & 4 & 5 & 6 & 7 & 8 & 9 & 10\end{array}$

32. I an not well liked because of my personality.

$\begin{array}{lllllllllll}0 & 1 & 2 & 3 & 4 & 5 & 6 & 7 & 8 & 9 & 10\end{array}$

33. I am not well liked wherever I do not bave money.

$\begin{array}{lllllllllll}0 & 1 & 2 & 3 & 4 & 5 & 6 & 7 & 8 & 9 & 10\end{array}$

When you finish working on this page go on to the next one. Do not return to this page. 
7.

STATEMENT: I am popular.

INSTRUCTIONS: Try to vividly imagine that the above statement

arplies to you. Now proceed to rate each one

of the causes which appear below the broken line on the basis of how well that iten describes you, with $0=$ not descriptive at all, and $10=$ very descriptive of me. You can mark any number between 0 and 10 depending on how well that item describes you.

not descriptive

of me at all

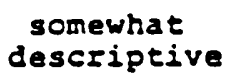

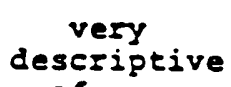

of me

$\begin{array}{lllllllllll}0 & 1 & 2 & 3 & 4 & 5 & 6 & 7 & 8 & 9 & 10\end{array}$

34. I am popular because I always try to be a Eun loving person.
0
12
23
45
6
7
8910

35. I am popular whenever my clothes are stylish.
0
12
2
34
5
67
910

36. I am popular because I am understanding.

$\begin{array}{lllllllllll}0 & 1 & 2 & 3 & 4 & 5 & 6 & 7 & 8 & 9 & 10\end{array}$

When you finish working on this page go on to the next ore. Do not seturn to this page. 
STATEMENT: I find it difficult to talk to people.

INSTRUCTIONS: Try to vividly imagine that the above statement applies to you. Now proceed to rate each one of the causes which appear below the broken ilne on the basis of how well that iten describes you, with $0=$ not descriptive at all, and lorvery descriptive of me. You can mark any number between 0 and 10 depending on how well that item describes you.

not descriptive

of me at all somewhat descriptive

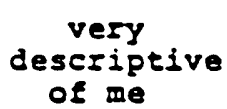

of ane

\section{$\begin{array}{lllllllllll}0 & 1 & 2 & 3 & 4 & 5 & 6 & 7 & 8 & 9 & 10\end{array}$}

37. I find it difficult to talk to people because I am not very intelligent.
123
45
6
8910

38. I find it difficult to talk to people when things are not going my way.
0
1
2
3
4.
5
6
7
$9 \quad 10$

39. I find it difficult to talk to people because I never try to be an understanding person.

$\begin{array}{lllllllllll}0 & 1 & 2 & 3 & 4 & 5 & 6 & 7 & 8 & 9 & 10\end{array}$

40. I find lt difficult to talk to people because my religious practices have failed to give me the power to succeed.

$\begin{array}{lllllllllll}0 & 1 & 2 & 3 & 4 & 5 & 6 & 7 & 8 & 9 & 10\end{array}$

41. I find 1t difficult to talk to people because talking to people takes a lot of effort.
456
$\begin{array}{llll}7 & 7 & 9 & 10\end{array}$

42. I find it difficult to talk to people wherever I don't make an effort to be outgoing.
0
1
23
4
56
$\begin{array}{lllll}6 & 7 & 8 & 9 & 10\end{array}$ 
STATEMENT: I get along well with people.

INSTRLCTIONS: TrY to vividly inagine that the above statement applies to you. Now proceed to rate each one of the causes which appear below the broken line on the basis of how well that item describes you, with onnot descriptive at all. and $10=v e r y$ descriptive of me. you can mark any number between 0 and 10 depending on how well that item describes you.

not descripelve

of me at all somewhat

descriptive

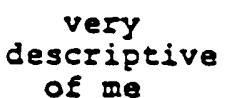

0

12

56

67

89

10

43. I get along well with people because that's the way the cards usually fall.

$\begin{array}{lllllllllll}0 & 1 & 2 & 3 & 4 & 5 & 6 & 7 & 8 & 9 & 10\end{array}$

44. I get along well with people because I have gotten God to love me.

$\begin{array}{lllllllllll}0 & 1 & 2 & 3 & 4 & 5 & 6 & 7 & 8 & 9 & 10\end{array}$

45. I get along well with people because getting along with people is easy.

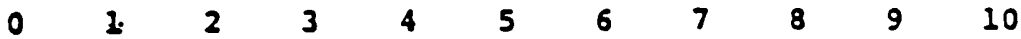

46. I get along well with people because I have a good sense of humor.

$\begin{array}{lllllllllll}0 & 1 & 2 & 3 & 4 & 5 & 6 & 7 & 8 & 9 & 10\end{array}$ 
STATEMENT: I find it difficult to make friends.

INSTRUCTIONS: TrY to vividly imagine that the above statenent applies to you. Now proceed to rate each one of the causes which appear below the broken line on the basis of how well that iter describes you, with $0=$ not descriptive at all. and lowvery descriptive of me. You can mark any number between 0 and 10 depending on how well that item describes you.

not descriptive

of we at all

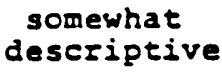

very
descriptive
of me

$$
\begin{array}{lllllllllll}
0 & 1 & 2 & 3 & 4 & 5 & 6 & 7 & 8 & 9 & 10
\end{array}
$$

47. I find it difficult to make friends because making friends takes a lot of persistence.
012
23
3
5
6
7
8910

48. I find it difficult to make friends because I never try to be friendly.

$\begin{array}{lllllllllll}0 & 1 & 2 & 3 & 4 & 5 & 6 & 7 & 8 & 9 & 10\end{array}$

49. I find it difficult to make friends because I don't usually seem to be at the right place at the right time.

$\begin{array}{lllllllllll}0 & 1 & 2 & 3 & 4 & 5 & 6 & 7 & 8 & 9 & 10\end{array}$

50. I find it difficult to make friends whenever I am with an ugly person.

$\begin{array}{lllllllllll}0 & 1 & 2 & 3 & 4 & 5 & 6 & 7 & 8 & 9 & 10\end{array}$

51. I find it difficult to make friends when I feel the need to be alone.

$\begin{array}{lllllllllll}0 & 1 & 2 & 3 & 4 & 5 & 6 & 7 & 8 & 9 & 10\end{array}$

52. I find it difficult to make friends wherever I do not work hard at it.

$\begin{array}{lllllllllll}0 & 1 & 2 & 3 & 4 & 5 & 6 & 7 & 8 & 9^{\circ} & 10\end{array}$

53. I find it difficult to make friends because I an shy.

$\begin{array}{lllllllllll}0 & 1 & 2 & 3 & 4 & 5 & 6 & 7 & 8 & 9 & 10\end{array}$

54. I find ft difficult to make friends because I have not made good contacts in the right places.

$\begin{array}{lllllllllll}0 & 1 & 2 & 3 & 4 & 5 & 6 & 7 & 8 & 9 & 10\end{array}$ 
Please answer the following questions:

1. Your age:

2. Your sex: Male Female

3. Your ethnic origin:

1. Anglo (white, anglosaxon or others of european descent)

2: Black (not of hispanic origin)

3. Cuban American

4. Other Hispanic

5. American Indian

6. Other (please specify:

4. Your occupation. Please be as specific as you can:

5. Your education. Indicate grade or highest degree obtain:

6. Your father's occupation. If he is retired, indicate his occupation immediately before his retirement. please be as specific as you can:

7. Your father's education. Indicate grade or highest degree obtained:

Thank you. 


\section{Reference Notes}

1. Escovar, L.A., Brown, G.A., and Rodriguez, R.R.

The EBR Attributional style questionnaire. Paper

presented at the meeting of the American Psychological

Association, Washington, D.C., August 1982 .

2. Peterson, C., Semmel, A., von Baeyer, C., Abramson,

L.Y., Metalsky, G.I., and Seligman, M.E.P. The

attributional style questionnaire. Unpublished

manuscript, University of Pennsylvania, 1982. 
Abramson, L.Y., Seligman, M.E.P., and Teasdale, J.D.

Learned helplessness in humans: Critique and reformulation.

Arkin, R.M., Appleman, A.J., and Burger, J.M. Social anxiety, self-presentation and the self-serving bias in causal attributions. Journal of Personality and Social Psychology, 1980, 38, 23-35.

Arkin, R.M. and Duvall, S. Focus of attention of actors and observers. Journal of Experimental Social Psychology, $1975, \underline{11}, 427-438$.

Broverman, I.K., Broverman, D.M., Clarkson, F.E., Rosenkrantz, P.S., and Vogel, S.R. Sex-role stereotypes and clinical judgments of mental health. Journal of Consulting and Clinical Psychology, 1970, 34, 1-7.

Costello, C.G. A critical review of Seligman's laboratory experiments on learned helplessness and depression in humans. Journal of Abnormal Psychology, 1978, 87, 21-31. Costrich, N., Feinstein, J., Kidder, L., Marecek, J., and Pascale, L. When stereotypes hurt: Three studies of penalties for sex-role reversal. Journal of Experimental Social Psychology, 1975, 11, 520-530.

Crandall, V.C., Katkovski, W., and Crandall, V.J. Children's beliefs in their own control of reinforcements in intellectual-academic achievement situations. Child Development, 1965, 36, 91-109. 
Deaux, K. and Emswiller, T. Explanations of successful performance on sex-linked tasks: What is skill for the male is luck for the female. Journal of Personality and Social Psychology, 1974, 29, 80-85.

Deaux, K. and Farris, E. Attributing the causes for one's own performance: The effects of sex, norms, and outcome. Journal of Research in Personality, 1977, 11, 59-72.

Diener, C.I. and Dweck, C.S. An analysis of learned helplessness: Continuous changes in performance, strategy and achievement cognitions following failure. Journal of Personality and Social Psychology, 1978, 36 , $451-462$

Dweck, C.S. and Bush, E.S. Sex differences in learned helplessness: I. Differential debilitation with peer and adult evaluators. Developmental Psychology, 1976, $12,147-156$

Dweck, C.S., Davidson, W., Nelson, S., and Enna, B. Sex differences in learned helplessness: II. The contingencies of evaluative feedback in the classroom and III. An experimental analysis. Developmental Psychology, 1978, 14, 268-276.

Dweck, C.S. and Gilliard, D. Expectancy statements as determinants of reactions to failure: Sex differences in persistence and expectancy change. Journal of Personality and Social Psychology, 1975, 33, 1077-1084. Dweck, C.S., Goetz, T.E., and Strauss, N.L. Sex differences in learned helplessness: IV. An experimental and naturalistic study of failure generalization and its 
mediators. Journal of Personality and Social Psychology, $1980, \underline{38}, 441-452$.

Dweck, C.S. and Reppucci, N.D. Learned helplessness and reinforcement responsibility in children. Journal of Personality and Social Psychology, 1973, 25, 109-116. Kukla, A. Attributional determinants of achievement related behavior. Journal of Personality and Social Psychology, $1972, \underline{21}, 166-174$.

Miller, D.T. Ego involvement and attributions for success and failure. Journal of Personality and Social Psychology, 1976, 34, 901-906.

Miller, W.R. and Seligman, M.E.P. Depression and learned helplessness in man. Journal of Abnormal Psychology, $1975, \underline{85}, 228-238$.

Nicholls, J.G. Causal attributions and other achievementrelated cognitions: Effects of task outcome, attainment value and sex. Journal of Personality and Social Psychology, 1975, 31, 379-389.

Nisbett, R.E., Caputo, C., Legant, P., and Marecek, J. Behavior as seen by the actor and as seen by the observer. Journal of Personality and Social Psychology, $1973, \underline{27}, 154-164$.

Overmier, J.B. and Seligman, M.E.P. Effects of inescapable shock upon subsequent escape and avoidance learning. Journal of Comparative and Physiological Psychology, $1967, \underline{63}, 23-33$. 
Radloff, L.S. and Monroe, M.K. Sex differences in helplessness with implications for depression. In L.S. Hanson's and R.S. Rapoza's (Eds.), Career Development and Counseling of women. Springfield, Illinois: Charles C. Thomas, 1978. Rizley, R. Depression and distortion in the attribution of causality. Journal of Abnormal Psychology, 1978, 87, $32-48$.

Seligman, M.E.P. Helplessness. San Francisco: W.H.

Freeman, 1975.

Seligman, M.E.P., Abramson, L.Y., Semmel, A., and von Baeyer, C. Depressive attributional style. Journal of Abnormal Psychology, 1979, 88, 242-247.

Sobel, R.S. The effects of success, failure and locus of control on post-performance attributions of causality. The Journal of General Psychology, 1974, 91, 29-34. Stein, A.H. and Bailey, M.M. The socialization of achievement motivation in females. Psychological Bulletin, 1973, 80, 345-366.

Strueffert, $S$. and strueffert, $S$. The effects of conceptual structure, failure and success on attributions of causality and interpersonal attitudes. Journal of Personality and Social psychology, 1969, 11, 138-147. Weiner, B. A theory of motivation for some classroom experiences. Journal of Educational Psychology, 1979, 71, $3-25$. 
Yarkin, K.L., Town, J.P., and Wallston, B.S. Blacks and women must try harder: Stimulus persons' race and sex in attributions of causality. Personality and Social Psychology Bulletin, $1982, \underline{8}, 21-24$. 
VITA

Title of Thesis: Actual and Perceived Sex Differences in Attributional Style for Affiliative Behavior

Full Name: Gretchen Allison Brown

Place and Date of Birth: Kansas City, Missouri August 16, 1958

Elementary and Secondary Education: Barstow School and Loretto in Kansas City

Colleges and Universities - Years Attended and Degrees University of Miami, August, 1976 to June, 1980 BA degree in Psychology

Florida International University, August, 1980 to December, 1982 is degree in Psychology

Membership in Learned or Honorary Societies

American Psychological Association Division 8

American Psychological Association Division 9

American Psychological Association Division 27

Publications: The EBR Attributional Style Questionnaire. Paper presented at the American Psychological Association Annual Meeting, Washington, D.C., August 1982. Co-author with Luis A. Escovar, Ph.D., and Rolando R. Rodriguez.

Major Department: Psychology

Minor (s): None

Date: $12 / 16 / 82$ signed: 